\title{
A Three Rate-Constant Kinetic Model for Permanganate Reactions Autocatalyzed by Colloidal Manganese Dioxide:
} The Oxidation of L-Phenylalanine

Joaquin F. Perez-Benito* and Jordi Ferrando

Departamento de Quimica Fisica, Facultad de Quimica, Universidad de Barcelona, Marti i Franques, 1, 08028 Barcelona, Spain 
ABSTRACT: The reduction of permanganate ion to $\mathrm{MnO}_{2}-\mathrm{Mn}_{2} \mathrm{O}_{3}$ soluble colloidal mixed oxide by L-phenylalanine in aqueous phosphate-buffered neutral solutions has been followed by a spectrophotometric method, monitoring the decay of permanganate ion at $525 \mathrm{~nm}$ and the formation of the colloidal oxide at $420 \mathrm{~nm}$. The reaction is autocatalyzed by the manganese product and three rate constants have been required to fit the experimental absorbance-time kinetic data. The reaction shows base catalysis and the values of the activation parameters at different $\mathrm{pHs}$ have been determined. A mechanism including both the non-autocatalytic and the autocatalytic reaction pathways, and in agreement with the available experimental data, has been proposed. Some key features of this mechanism are the following: (i) of the two predominant forms of the amino acid, the anionic form exhibits a stronger reducing power than the zwitterionic form; (ii) the non-autocatalytic reaction pathway starts with the transfer of the hydrogen atom in the $\alpha$ position of the amino acid to permanganate ion; and (iii) the autocatalytic reaction pathway involves the reduction of $\mathrm{Mn}(\mathrm{IV})$ to $\mathrm{Mn}$ (II) by the amino acid and the posterior re-oxidation of $\mathrm{Mn}(\mathrm{II})$ to $\mathrm{Mn}(\mathrm{IV})$ by permanganate ion.

KEYWORDS: Activation parameters; Amino acid; Manganese(III); Mechanism; Rate constants; Runge-Kutta method. 


\section{INTRODUCTION}

Potassium permanganate is one of the most useful reactants in the chemistry laboratory, and it is widely employed as a versatile oxidizing agent. ${ }^{1-3}$ On their part, $\alpha$-amino acids are important biological compounds, since they are the essential constituents utilized by nature in the synthesis of proteins. ${ }^{4}$ Oxidation of $\alpha$-amino acids is a topic of some interest in relation to cell metabolism. For instance, oxygen free radicals are known to initiate the oxidative degradation of proteins. ${ }^{5}$

The oxidation of $\alpha$-amino acids by permanganate ion can be used as a simple chemical model for other related reactions of biological importance. As a result, the scientific literature concerning the permanganate-amino acid reactions is abundant. In particular, these redox reactions have been studied in both acidic ${ }^{6-24}$ and neutral solutions. ${ }^{25-41}$ An important finding of these kinetic studies is the autocatalysis observed in both media.

Autocatalysis is an interesting phenomenon at the theoretical level because of the relatively scarce information existing on this topic. As happens with all catalytic reactions, in the mechanism of autocatalytic processes at least two reaction pathways are involved, one corresponding to the reaction taking place without involvement of the autocatalytic product and the other corresponding to the autocatalytic process, the rate-determining step being different for each reaction pathway. An integrated rate equation that allows the determination of the two rate constants associated to the non-autocatalytic and autocatalytic reaction pathways has been reported. ${ }^{42-44}$ However, some deviations from the proposed mathematical model are evident from the experimental kinetic data published for the permanganate-glycine reaction. ${ }^{45}$ Moreover, a case of delayed autocatalysis has been reported for the permanganateamino acid reactions under acidic conditions. ${ }^{46-50}$ Although delayed autocatalysis is not interpretable by the two rate-constant model, it has also been observed in at least another 
permanganate reaction. ${ }^{51}$ As a consequence, a new model has now been developed that allows the determination of three rate constants for each kinetic experiment. This model takes into account the change in the colloid surface composition occurring during the permanganate reaction due to reduction of $\mathrm{Mn}(\mathrm{IV})$ by the excess amino acid, whereas the former two rateconstant model did not. The simultaneous determination of three rate constants is scantily represented in the literature of chemical kinetics, the chromium(VI) oxidation of thiols being a notable exception. ${ }^{52-55}$

An outstanding feature of the permanganate-amino acid reactions is that autocatalysis has been found in both acidic and neutral solutions, in spite of the fact that the manganese reduction product is different in the two media, manganese(II) ion under acidic conditions and colloidal manganese dioxide (in the form of discrete nanoparticles ${ }^{56}$ ) at near-neutrality $\mathrm{pH}$. As

a consequence, doubts have arisen on the identity of the species responsible for the autocatalytic behavior, especially on whether the same autocatalyst is involved in both cases. The present work will focus on the nature of the autocatalytic agent, and three possibilities [manganese(II), manganese(III) and manganese(IV)] will be considered, checking the consistency of each alternative against the available experimental data.

\section{EXPERIMENTAL METHODS}

2.1. Materials and Methods. The solvent used in all the experiments was water previously purified by deionization followed by treatment with a Millipore Synergy UV system (milli-Q quality, $\kappa=0.05 \mu \mathrm{S} / \mathrm{cm}$ at $\left.25.0{ }^{\circ} \mathrm{C}\right)$. The oxidant was potassium permanganate $\left(\mathrm{KMnO}_{4}\right.$, Panreac, purity $\geq 99.0 \%)$ and the reductant L-phenylalanine $\left(\mathrm{C}_{6} \mathrm{H}_{5}-\mathrm{CH}_{2}-\mathrm{CH}\left(\mathrm{NH}_{2}\right)-\mathrm{COOH}\right.$, Sigma-Aldrich, purity $\geq 98.0 \%$ ). The components of the buffer were potassium dihydrogen 
phosphate $\left(\mathrm{KH}_{2} \mathrm{PO}_{4}\right.$, Merck, purity $\left.\geq 99.5 \%\right)$ and potassium hydrogen phosphate trihydrate $\left(\mathrm{K}_{2} \mathrm{HPO}_{4} \cdot 3 \mathrm{H}_{2} 0\right.$, Merck, purity $\left.\geq 99.0 \%\right)$. Potassium chloride $(\mathrm{KCl}$, Merck, purity $\geq 99.5 \%)$ was used as inert electrolyte.

The $\mathrm{pH}$ measurements were done by means of a Metrohm $605 \mathrm{pH}-$ meter, provided with a digital presentation till the third decimal figure $( \pm 0.001 \mathrm{pH})$ and a combination electrode, calibrated with the aid of two commercial buffers at pH $4.00 \pm 0.02$ (Merck) and $7.00 \pm 0.01$ (Sigma-Aldrich). The temperature was kept constant by means of a Julabo thermostatic bath provided with a digital reading $\left( \pm 0.1^{\circ} \mathrm{C}\right)$. The spectra were recorded and the absorbances measured with a Shimadzu 160 A UV-Vis spectrophotometer $( \pm 0.001 A)$.

2.2. Kinetic Experiments. In most of the experiments the initial concentration of the reducing agent (L-phenylalanine) was much higher than that of the oxidant (permanganate ion) in order to attain an approximately constant concentration of the amino acid (isolation method). In the experiments where the initial concentration of the latter was not large enough, a special program was developed to take into account the decrease of its concentration as the reaction progressed based on the permanganate/amino acid stoichiometric ratio.

The kinetic runs were followed at two different wavelengths (420 and $525 \mathrm{~nm}$ ), measuring the absorbances periodically at time intervals of 30-600 s. The wavelength of $525 \mathrm{~nm}$ corresponds to the highest peak of the electronic visible spectrum of permanganate ion and that of $420 \mathrm{~nm}$ to the wavelength at which permanganate ion is almost transparent; these wavelengths allowed to monitor the decay of permanganate ion and the formation of the manganese reaction product, respectively. All the kinetic experiments were duplicated in order to ascertain the reproducibility of the rate constants.

2.3. Kinetic Calculations. Two computer programs were written in BASIC language, one for the determination of two rate constants $\left(k_{1}\right.$ and $\left.k_{2}\right)$, and the other for the determination of three rate constants $\left(k_{1}, k_{2}\right.$ and $\left.k_{3}\right)$. In the first program $k_{1}$ and $k_{2}$ correspond to the non- 
autocatalytic and autocatalytic reaction pathways, respectively. In the second program $k_{1}$ is associated to the non-autocatalytic pathway, whereas both $k_{2}$ and $k_{3}$ are associated to the autocatalytic one, allowing the introduction into the mathematical model of a long-lived, non in steady-state intermediate. The corresponding calculations were implemented on a Sony Vaio personal computer.

\section{RESULTS}

3.1. Visible Spectra. A periodical scanning of the reaction mixture revealed the existence of two isosbestic points at 467 and $692 \mathrm{~nm}$ (Figure 1, top). The spectrum of the manganese reduction product showed the typical upward-concave band covering the whole visible region corresponding to absorption + dispersion by soluble colloidal $\mathrm{MnO}_{2},{ }^{57}$ as well as a shoulder corresponding to light absorption by $\mathrm{Mn}(\mathrm{III}) .{ }^{58-60}$ On standing and at high L-phenylalanine concentration, the peak at $462 \mathrm{~nm}$ corresponding to $\mathrm{Mn}(\mathrm{III})$ became more definite as the spectrum decayed because of the reduction of $\mathrm{Mn}(\mathrm{IV})$ by the amino acid (Figure 1, bottom). The stability of this $\mathrm{Mn}$ (III) species (detectable for one week after completion of the permanganate/amino acid reaction) suggests that it was a colloidal oxide $\left(\mathrm{Mn}_{2} \mathrm{O}_{3}\right)$ rather than an aqueous species, either $\mathrm{Mn}^{3+}$ (instable by dismutation) or a $\mathrm{Mn}(\mathrm{III})$ complex with Lphenylalanine (instable by internal redox reaction).

Figure 1 
3.2. From the Experimental Absorbance-Time Data to the Reaction Rate. The permanganate concentrations were obtained at different instants during the course of the reaction from the experimental absorbance readings at two wavelengths by means of the equation:

$$
\left[\mathrm{MnO}_{4}^{-}\right]_{\mathrm{t}}=\frac{1}{\varepsilon_{\mathrm{R}, 525} l}\left[A(525)_{\mathrm{t}}-\frac{A(525)_{\infty}}{A(420)_{\infty}} A(420)_{\mathrm{t}}\right]
$$

where $A(420)_{\mathrm{t}}$ and $A(525)_{\mathrm{t}}$ are the absorbances at 420 and $525 \mathrm{~nm}$ at time $t, A(420)_{\infty}$ and $A(525)_{\infty}$ the corresponding values at the end of the reaction, $\varepsilon_{\mathrm{R}, 525}=2420 \pm 10 \mathrm{M}^{-1} \mathrm{~cm}^{-1}$ the molar absorption coefficient of the limiting reactant (permanganate ion) at $525 \mathrm{~nm}$ and $l=1$ $\mathrm{cm}$ the optical path length. Equation 1 is useful to obtain correct values of the permanganate concentration in the presence of a colloidal species formed as a reaction product because it does not require that the values of the molar absorption coefficients of the colloidal product ( $\varepsilon_{\mathrm{P}, 420}$ and $\varepsilon_{\mathrm{P}, 525}$ ) be constant during the kinetic runs, but only their ratio at the two wavelengths considered $\left(\varepsilon_{\mathrm{P}, 525} / \varepsilon_{\mathrm{P}, 420}=A(525)_{\infty} / A(420)_{\infty}\right)$.

The values of the reaction rate were obtained from those of the permanganate concentration by means of the finite difference method. This mathematical procedure of approximate derivation allows the calculation of the rate at time $t+\Delta t / 2$ from the permanganate concentrations $(c)$ at times $t$ and $t+\Delta t$ as:

$$
v=-\frac{\mathrm{d}\left[\mathrm{MnO}_{4}^{-}\right]}{\mathrm{d} t} \approx \frac{c(t)-c(t+\Delta t)}{\Delta t}
$$


This method allows calculating the reaction rate with a very low systematic error provided that the time interval chosen $(\Delta t)$ is small enough.

The rate of the permanganate/L-phenylalanine reaction has been plotted as a function of time. We can see that the rate versus time plots are bell-shaped and that the ratio between the maximum value of the reaction rate and its initial value tended to decrease as the initial permanganate concentration decreased. For instance, whereas at high initial permanganate concentration $\left(1.00 \times 10^{-3} \mathrm{M}\right)$ a ratio of 2.36 was found (Figure 2, top), at low initial permanganate concentration $\left(4.00 \times 10^{-4} \mathrm{M}\right)$ the ratio was only 1.53 (Figure 2, bottom).

\section{Figure 2}

3.3. Two Rate-Constant Kinetic Model for Autocatalysis. The simplest form of the differential rate law for an autocatalytic reaction assumes that both reaction pathways are of first order in the limiting reactant (permanganate ion) and that the autocatalytic pathway is also of first order in the autocatalyst (colloidal manganese dioxide). Hence:

$$
v=k_{1}\left[\mathrm{MnO}_{4}^{-}\right]+k_{2}\left[\mathrm{MnO}_{4}^{-}\right]\left[\mathrm{MnO}_{2}\right]
$$

where $k_{1}$ and $k_{2}$ (the pseudo-rate constants for the non-autocatalytic and autocatalytic reaction pathways, respectively) are dependent on both the amino acid concentration (in large excess) and the $\mathrm{pH}$. Now, assuming that all the manganese intermediates are in steady state and, so, in negligible concentration with respect to $\mathrm{Mn}(\mathrm{VII})$ and $\mathrm{Mn}(\mathrm{IV})$, eq 3 can be rewritten as:

$$
v=k_{1} c+k_{2} c\left(c_{\mathrm{o}}-c\right)
$$


where $c_{\mathrm{o}}$ is the initial permanganate concentration.

This two-rate constant kinetic model can explain the fact that the bell-shaped profile of the reaction rate versus time plots tends to disappear as the initial concentration of the limiting reactant decreases (Figure 2), since it is easy to demonstrate from eq 4 that those plots show a maximum only when:

$$
c_{\mathrm{o}} \geq \frac{k_{1}}{k_{2}}
$$

Equation 4 can be rewritten in a linearized way as:

$$
\frac{v}{c}=\left(k_{1}+k_{2} c_{\mathrm{o}}\right)-k_{2} c
$$

Equation 6 predicts a linear plot when the rate-permanganate concentration ratio is plotted against the permanganate concentration at different instants during the course of the reaction. A typical example can be seen in Figure 3. For a pseudo-first order kinetics $\left(k_{2}=0\right)$ the $v / c$ ratio would be expected to remain constant $\left(v / c=k_{1}\right)$ as the reaction progresses. However, an increase of that ratio can be observed in Figure 3, indicating again the existence of an autocatalytic phenomenon. Although the first stretch is approximately linear, a definite upward-concave curvature can be seen at high reaction times, indicating that the two rateconstant kinetic model is insufficient to explain the behavior of the permanganate/Lphenylalanine reaction.

Figure 3 
3.4. Reduction of Colloidal manganese Dioxide. Some experiments suggest the type of modification that must be introduced in the former simplified model to fit the experimental data. As shown in Figure 4 (top), the absorbance at $420 \mathrm{~nm}$ increased uniformly from the reaction start because of the accumulation of colloidal $\mathrm{MnO}_{2}$ but, once permanganate ion was absent from the reaction medium, it started to decline due to the reduction of colloidal $\mathrm{MnO}_{2}$ by the amino acid in excess. From a pseudo-first order plot corresponding to the stretch of decay of $A(420)$, the rate constant $k=(5.29 \pm 0.10) \times 10^{-4} \mathrm{~s}^{-1}$ could be inferred for the reduction of $\mathrm{Mn}(\mathrm{IV})$ at $25.0^{\circ} \mathrm{C}$ (Figure 4 , bottom). The existence of this reduction process is consistent with the spectral changes recorded once permanganate ion disappeared completely from the reaction medium (Figure 1, bottom). Actually, reduction of water-soluble colloidal manganese dioxide by the amino acids L-cysteine, ${ }^{61}$ L-tryptophan $^{62}$ and L-tyrosine ${ }^{63}$ in acidic medium has been reported.

Figure 4

3.5. Three Rate-Constant Kinetic Model for Autocatalysis. Since the experimental results indicate that $\mathrm{Mn}(\mathrm{IV})$ is reduced by the excess amino acid once the permanganate reaction is over, it seems plausible to assume that the same reduction takes place during the whole course of the permanganate-amino acid reaction, but its effects cannot be observed whilst permanganate is present because of re-oxidation of the low oxidation-state manganese species by permanganate. To take into account this situation, the simplified mechanism shown in Scheme 1 has been developed, where the process of reduction of $\mathrm{Mn}$ (VII) to $\mathrm{Mn}(\mathrm{IV})$ by Lphenylalanine is governed by rate constant $k_{1}$, the reduction of $\mathrm{Mn}(\mathrm{IV})$ to $\mathrm{Mn}$ (II) by the excess amino acid is governed by rate constant $k_{2}$, and the re-oxidation of $\mathrm{Mn}$ (II) by $\mathrm{Mn}$ (VII) yielding both of them $\mathrm{Mn}(\mathrm{IV})$ is is governed by rate constant $k_{3}$. 


\section{Scheme 1}

The differential equations corresponding to this simplified mechanism are the following:

$$
\begin{aligned}
& \frac{\mathrm{d}[\mathrm{Mn}(\mathrm{VII})]}{\mathrm{d} t}=-k_{1}[\mathrm{Mn}(\mathrm{VII})]-k_{3}[\mathrm{Mn}(\mathrm{VII})][\mathrm{Mn}(\mathrm{II})] \\
& \frac{\mathrm{d}[\mathrm{Mn}(\mathrm{IV})]}{\mathrm{d} t}=k_{1}[\mathrm{Mn}(\mathrm{VII})]-k_{2}[\mathrm{Mn}(\mathrm{IV})]+2 k_{3}[\mathrm{Mn}(\mathrm{VII})][\mathrm{Mn}(\mathrm{II})] \\
& \frac{\mathrm{d}[\mathrm{Mn}(\mathrm{II})]}{\mathrm{d} t}=k_{2}[\mathrm{Mn}(\mathrm{IV})]-k_{3}[\mathrm{Mn}(\mathrm{VII})][\mathrm{Mn}(\mathrm{II})]
\end{aligned}
$$

where $k_{1}, k_{2}$ and $k_{3}$ are pseudo-rate constants (L-phenylalanine assumed in large excess with respect to permanganate ion). Equations 7-9 have been integrated for each kinetic experiment by means of a numerical approximate procedure, the fourth order Runge-Kutta method. ${ }^{64}$ In this way, once known the initial concentration of $\operatorname{Mn}(\mathrm{VII})\left(c_{\mathrm{o}}\right)$, as well as those of $\mathrm{Mn}(\mathrm{IV})$ and $\mathrm{Mn}(\mathrm{II})$ (both equal to 0), the concentrations of the three species at different instants during the course of the reaction could be obtained, using to that end short time intervals ( $\Delta t=$ 30-600 s, depending on the experimental conditions). A BASIC computer program was developed for the optimization of the values of the three rate constants $\left(k_{1}, k_{2}\right.$ and $\left.k_{3}\right)$ leading to a minimum of the average error calculated as:

$$
E=\frac{\sum_{\mathrm{i}=1}^{N}\left|A_{\mathrm{i}, \mathrm{cal}}-A_{\mathrm{i}, \exp }\right|}{N}
$$


where $A_{\mathrm{i} \text {,cal }}$ and $A_{\mathrm{i}, \mathrm{exp}}$ are the calculated and experimental absorbances, respectively, and $N$ is the number of time-absorbance datum couples for each kinetic run. The values of $E$ for 86 experiments were within the range $3.13 \times 10^{-4}-1.03 \times 10^{-3}$. An example of the excellent accordance between the calculated and experimental absorbances for a typical kinetic run is shown in Figure 5.

\section{Figure 5}

3.6. Comparison between Models. The ratio of the calculated and experimental absorbances at $525 \mathrm{~nm}$ has been represented as a function of time for a typical kinetic run. When the two rate-constant model was used (Figure 6, bottom) the errors were larger than when using the three rate-constant model (Figure 6, top). Moreover, whereas in the first case zones of defect $\left(A(525)_{\text {cal }} / A(525)_{\exp }<1\right)$ and excess $\left(A(525)_{\text {cal }} / A(525)_{\exp }>1\right)$ systematic errors followed one after another, in the second case the errors were essentially of accidental nature, as shown by the continuous crossing of the $A(525)_{\mathrm{cal}} / A(525)_{\exp }=1$ horizontal line. These results confirmed that the three rate-constant kinetic model represents an improvement over the former model.

\section{Figure 6}

3.7. Kinetic Results. Rate constants $k_{1}$ and $k_{3}$ decreased as the initial permanganate concentration increased, whereas $k_{2}$ increased (Table 1). Although true rate constants should not depend on the initial concentration of the limiting reactant, the existence of such dependence is a phenomenon rather generalized in kinetic studies of autocatalytic reactions

concerning not only the reduction of permanganate ion, ${ }^{65}$ but also that of colloidal $\mathrm{MnO}_{2}{ }^{66}$ This dependence can be partially explained by a change in the size and surface composition of the colloidal species. Actually, an increase of the initial permanganate concentration is 
expected to result in an increase of the average colloidal particle size as well as in a decrease of the level of reduction of surface $\mathrm{Mn}(\mathrm{IV})$ to the lower $\mathrm{Mn}(\mathrm{III}) / \mathrm{Mn}(\mathrm{II})$ oxidation sates.

\section{Table 1}

Rate constants $k_{1}$ and $k_{3}$ increased linearly as the L-phenylalanine concentration increased (order 1), whereas $k_{2}$ remained almost unchanged (order 0), as can be seen in Figure 7. The intercept for the $k_{1}$ versus [L-phenylalanine] plot (Figure 7, top) was clearly positive, $(7.4 \pm$

$0.9) \times 10^{-6} \mathrm{~s}^{-1}$. The intercept for the $k_{3}$ versus [L-phenylalanine] plot (Figure 7, bottom) was negligible within the experimental error, $-0.01 \pm 0.02 \mathrm{M}^{-1} \mathrm{~s}^{-1}$. Addition of the inert electrolyte $\mathrm{KCl}$ to the solution resulted in a decrease of the $\mathrm{pH}$, an increase of rate constant $k_{1}$ and a decrease of $k_{2}$, whereas $k_{3}$ showed no appreciable effect (Table 2).

\section{Figure 7}

\section{Table 2}

The three experimental rate constants increased with increasing $\mathrm{pH}$ (base catalysis), and this effect was studied at five different temperatures in the range $20.0-40.0^{\circ} \mathrm{C}$. Their plots versus the reciprocal of the hydrogen ion concentration showed a certain downward-concave curvature in the cases of both $k_{1}$ (Figure 8, top) and $k_{3}$ (Figure 8, bottom) and an upwardconcave curvature in the case of $k_{2}$ (Figure 8 , middle). However, for simplicity reasons, the experimental data were approximately fitted to rate constant versus $\left[\mathrm{H}^{+}\right]^{-1}$ linear plots.

\section{Figure 8}


Application of both the Arrhenius and Eyring equations allowed the determination of the apparent (pH-dependent) activation parameters associated to the rate constants $k_{1}$ (Table 3 ), $k_{2}$ (Table 4) and $k_{3}$ (Table 5). The apparent activation energy obtained for $k_{1}$ was roughly independent of $\mathrm{pH}$, whereas that of $k_{2}$ increased strongly with increasing $\mathrm{pH}$ and that of $k_{3}$ decreased slightly. The apparent values of the standard activation enthalpy at different $\mathrm{pHs}$ were strongly correlated with those of the standard activation entropy for rate constants $k_{2}$ and $k_{3}$, but weakly correlated in the case of $k_{1}$ (Figure 9). The corresponding slopes for the linear enthalpy-entropy plots yielded the values of the isokinetic temperatures $T_{\mathrm{ik}}=229 \pm 99$ (for $k_{1}$ ), $277 \pm 6$ (for $k_{2}$ ) and $350 \pm 29$ (for $k_{3}$ ) K. It thus seems that stronger $\mathrm{pH}$ dependence of the apparent activation energy correlates with higher coupling of the apparent activation enthalpyentropy values.

\section{Table 3}

\section{Table 4}

\section{Table 5}

Figure 9

The intercepts and slopes of both the $k_{1}$ versus $\left[\mathrm{H}^{+}\right]^{-1}$ and $k_{3}$ versus $\left[\mathrm{H}^{+}\right]^{-1}$ linear plots, as well as the slopes of the $k_{2}$ versus $\left[\mathrm{H}^{+}\right]^{-1}$ linear plots (the corresponding intercepts were negligible), at different temperatures were in excellent agreement with the Arrhenius equation (Figure 10). Moreover, they also fulfilled the Eyring equation, yielding the $\mathrm{pH}$-independent activation parameters listed in Table 6 .

Figure 10

Table 6 


\section{DISCUSSION}

4.1. Stoichiometric Equations. According to the information reported in the literature concerning the reaction products, ${ }^{67}$ the stoichiometries of the permanganate oxidation of $\alpha$ amino acids to yield $\mathrm{Mn}(\mathrm{IV})$ and $\mathrm{Mn}(\mathrm{III})$ can be written, respectively, as:

$$
\begin{aligned}
& 2 \mathrm{MnO}_{4}{ }^{-}+3 \mathrm{NH}_{3}{ }^{+} \mathrm{CHRCO}_{2}{ }^{-}+5 \mathrm{H}^{+}=2 \mathrm{MnO}_{2}+3 \mathrm{NH}_{4}{ }^{+}+3 \mathrm{RCHO}+3 \mathrm{CO}_{2}+\mathrm{H}_{2} \mathrm{O} \\
& 2 \mathrm{MnO}_{4}{ }^{-}+4 \mathrm{NH}_{3}{ }^{+} \mathrm{CHRCO}_{2}{ }^{-}+6 \mathrm{H}^{+}=\mathrm{Mn}_{2} \mathrm{O}_{3}+4 \mathrm{NH}_{4}{ }^{+}+4 \mathrm{RCHO}+4 \mathrm{CO}_{2}+\mathrm{H}_{2} \mathrm{O}
\end{aligned}
$$

where in the case of the present study $\mathrm{R}=\mathrm{C}_{6} \mathrm{H}_{5} \mathrm{CH}_{2}$ (phenylmethyl). Given that aldehydes are readily oxidized by permanganate ion in neutral solution, ${ }^{68}$ further oxidation of RCHO to the carboxylate ion $\mathrm{RCOO}^{-}$is expected unless a large excess of the $\alpha$-amino acid is used.

4.2. Mechanism Associated to Rate Constant $\boldsymbol{k}_{\mathbf{1}}$. The mechanism proposed for the nonautocatalytic part of the permanganate/L-phenylalanine reaction consists of the following steps:

$$
\begin{aligned}
& { }^{+} \mathrm{H}_{3} \mathrm{NCHRCO}_{2} \stackrel{K_{\mathrm{I}}}{\rightleftarrows} \mathrm{H}_{2} \mathrm{NCHRCO}_{2}{ }^{-}+\mathrm{H}^{+} \\
& \mathrm{MnO}_{4}{ }^{-}+{ }^{+} \mathrm{H}_{3} \mathrm{NCHRCO}_{2}{ }^{-} \frac{k_{\mathrm{II}}}{\text { slow }} \mathrm{HMnO}_{4}{ }^{-}+\mathrm{H}_{2} \mathrm{NC}^{\cdot} \mathrm{RCO}_{2}{ }^{-}+\mathrm{H}^{+} \\
& \mathrm{MnO}_{4}{ }^{-}+\mathrm{H}_{2} \mathrm{NCHRCO}_{2}{ }^{-} \frac{k_{\mathrm{III}}}{\text { slow }} \mathrm{HMnO}_{4}{ }^{-}+\mathrm{H}_{2} \mathrm{NC}^{-} \mathrm{RCO}_{2}{ }^{-} \\
& \mathrm{H}_{2} \mathrm{NC}^{-} \mathrm{RCO}_{2}{ }^{-}+\mathrm{H}_{2} \mathrm{O} \longrightarrow \mathrm{H}_{2} \mathrm{NC}^{\cdot} \mathrm{HR}+\mathrm{CO}_{2}+\mathrm{HO}^{-}
\end{aligned}
$$




$$
\begin{aligned}
& \mathrm{MnO}_{4}{ }^{-}+\mathrm{H}_{2} \mathrm{NC}^{\cdot} \mathrm{HR} \longrightarrow \mathrm{HMnO}_{4}{ }^{-}+\mathrm{HN}=\mathrm{CHR} \\
& \mathrm{HN}=\mathrm{CHR}+\mathrm{H}_{3} \mathrm{O}^{+} \longrightarrow \mathrm{NH}_{4}{ }^{+}+\mathrm{RCHO} \\
& \mathrm{HMnO}_{4}{ }^{-} \rightleftarrows \mathrm{MnO}_{4}{ }^{-}+\mathrm{H}^{+} \\
& \mathrm{HMnO}_{4}{ }^{-}+\mathrm{MnO}_{4}{ }^{-} \longrightarrow \mathrm{HMnO}_{4}{ }^{-}+\mathrm{MnO}_{4}{ }^{-} \\
& \mathrm{HMnO}_{4}{ }^{2-}+\mathrm{H}_{2} \mathrm{NCHRCO}_{2}{ }^{-} \longrightarrow \mathrm{MnO}_{2}+\mathrm{H}_{2} \mathrm{NC}^{-} \mathrm{RCO}_{2}{ }^{-}+2 \mathrm{HO}^{-} \\
& n \mathrm{MnO}_{2} \longrightarrow\left(\mathrm{MnO}_{2}\right)_{\mathrm{n}}
\end{aligned}
$$

Two reaction pathways can be distinguished in this part of the reaction, the corresponding rate-determining steps being the oxidations of the zwitterionic (eq 14) and anionic (eq 15) forms of the amino acid, leading to the formation of an organic free radical. Involvement of free radicals in the permanganate oxidation of amino acids is consistent with the finding that the permanganate/L-serine reaction initiates the polymerization of acrylamide ${ }^{69}$ Formation of an imine as an intermediate (eq 17) is a widespread assumption in the chemical literature concerning the permanganate oxidation of both amines ${ }^{70}$ and amino acids, ${ }^{29}$ and it is based on experimental stoichiometric results. ${ }^{71}$ This part of the mechanism finishes with the formation of colloidal $\mathrm{MnO}_{2}$ particles as a temporarily dissolved species from the individual molecules (eq 22).

By application of both the quasi-equilibrium and steady-state approximations, the following mathematical expression is obtained for the first experimental rate constant:

$$
k_{1}=\frac{\left(k_{\mathrm{II}}\left[\mathrm{H}^{+}\right]+K_{\mathrm{I}} k_{\mathrm{III}}\right)[\mathrm{L}-\mathrm{Phe}]_{\mathrm{T}}}{2\left(K_{\mathrm{I}}+\left[\mathrm{H}^{+}\right]\right)}
$$


where $[\mathrm{L}-\mathrm{Phe}]_{\mathrm{T}}$ is the total L-phenylalanine concentration (both the zwitterionic and anionic forms included). Equation 23 is consistent with the linearity of the $k_{1}$ versus [Lphenylalanine] plot (Figure 7, top). The finding that the corresponding intercept was positive suggests the existence of a slow thermal decomposition of permanganate ion in the absence of amino acid. $^{72}$

Addition of $\mathrm{KCl}$ to the solution resulted in both a decrease of $\mathrm{pH}$ (because an increase of the ionic strength led to a decrease of the $\mathrm{p} K_{\mathrm{a}}$ of $\mathrm{H}_{2} \mathrm{PO}_{4}{ }^{-}$) and an increase of $k_{1}$. Since the reaction had base catalysis, it follows that an increase of the ionic strength alone (without $\mathrm{pH}$ change) would have resulted in an increase of $k_{1}$ even stronger than that experimentally observed. This is consistent with the fact that the theoretical rate constant $k_{\text {III }}$ corresponds to the elementary reaction of two anions (eq 15), since the presence of inert ions $\left(\mathrm{K}^{+}\right.$and $\left.\mathrm{Cl}^{-}\right)$in the solution weakened the electrostatic repulsion between the two reactants (permanganate ion and the anionic form of the amino acid), thus increasing the frequency of their collisions.

Equation 23 is consistent with the increase of the experimental rate constant $k_{1}$ with increasing $\mathrm{pH}$ (base catalysis) provided that $k_{\mathrm{III}}>k_{\mathrm{II}}$. Fulfillment of this condition is indeed plausible because the anionic form of the amino acid has a higher electronic density (and so a higher reducing power) than the zwitterionic form.

The value of the equilibrium constant associated to eq 13 has been reported $\left(K_{\mathrm{I}}=5.16\right.$ $\times 10^{-10} \mathrm{M}, \mathrm{p} K_{\mathrm{a}}=9.29$, at zero ionic strength and $\left.25.0^{\circ} \mathrm{C}\right) .{ }^{73}$ This means that for the nearneutrality solutions of the present work $(\mathrm{pH} 6.66-7.47)$ the condition $K_{\mathrm{I}}<<\left[\mathrm{H}^{+}\right]$is fulfilled, given that the zwitterionic form of the amino acid was predominant. According to this new approximation, eq 23 yields: 


$$
k_{1}=\frac{1}{2}\left(k_{\mathrm{II}}+\frac{K_{\mathrm{I}} k_{\mathrm{III}}}{\left[\mathrm{H}^{+}\right]}\right)[\mathrm{L}-\mathrm{Phe}]_{\mathrm{T}}
$$

in agreement with the existence of $k_{1}$ versus $\left[\mathrm{H}^{+}\right]^{-1}$ linear plots (Figure 8, top), the intercepts corresponding to the reaction of permanganate ion with the zwitterionic form of the amino acid in the solution and the slopes to the reaction with the anionic form. Hence, according to eq 24 and the activation parameters given in Table 6, we can conclude that the $\mathrm{pH}$ independence of the apparent activation energy associated to rate constant $k_{1}$ experimentally observed (Table 3) can be explained because the temperature dependence of rate constant $k_{\mathrm{II}}$ $\left(E_{\mathrm{a}, \mathrm{II}}=70 \pm 2 \mathrm{~kJ} \mathrm{~mol}^{-1}\right)$ is quite similar to that of the product $K_{\mathrm{I}} k_{\mathrm{III}}\left(\Delta H_{\mathrm{I}}^{\mathrm{o}}+E_{\mathrm{a}, \mathrm{III}}=68 \pm 2\right.$ $\left.\mathrm{kJ} \mathrm{mol}^{-1}\right)$.

Application of eq 24 to the $\mathrm{pH}$-temperature crossed experimental data, along with the thermodynamic parameters reported for equilibrium constant $K_{\mathrm{I}}{ }^{73}$ allowed the determination of rate constants $k_{\mathrm{II}}$ and $k_{\mathrm{III}}$ as well as their associated activation parameters (Table 7). The value obtained for the ratio of those two rate constants was $k_{\mathrm{III}} / k_{\mathrm{II}}=248 \pm 96$, and the activation energy associated to $k_{\mathrm{III}}\left(23 \pm 2 \mathrm{~kJ} \mathrm{~mol}^{-1}\right)$ was much lower than that associated to $k_{\text {II }}\left(70 \pm 2 \mathrm{~kJ} \mathrm{~mol}^{-1}\right)$. These findings are again consistent with the higher electronic density of the amino acid anionic form (strong reducing agent) with respect to the zwitterionic form (weak reducing agent).

\section{Table 7}

The kinetics of the reaction of permanganate ion with L-phenylalanine in neutral aqueous solutions resembles those of its reactions with other $\alpha$-amino acids. For instance, besides 
being all of them autocatalyzed by colloidal $\mathrm{MnO}_{2}$, the activation energy for the nonautocatalytic reaction pathway in the oxidation of L-alanine is $74.0 \mathrm{~kJ} \mathrm{~mol}^{-1}{ }^{29}$ quite close to the values found in Table 3 for the same reaction pathway in the oxidation of Lphenylalanine. This suggests that the permanganate/ $\alpha$-amino acid reactions follow a common mechanism, the side group $\mathrm{R}$ not being directly attacked by the oxidant.

4.3. Mechanism Associated to Rate Constant $\boldsymbol{k}_{2}$. The following steps are proposed for this part of the reaction, corresponding to the beginning of the autocatalytic reaction pathway:

$$
\begin{aligned}
& \left(\mathrm{MnO}_{2}\right)_{\mathrm{n}}+{ }^{+} \mathrm{H}_{3} \mathrm{NCHRCO}_{2}{ }^{-} \stackrel{K_{\mathrm{IV}}}{\rightleftarrows}\left(\mathrm{MnO}_{2}\right)_{\mathrm{n}}-{ }^{+} \mathrm{H}_{3} \mathrm{NCHRCO}_{2}{ }^{-} \\
& \left(\mathrm{MnO}_{2}\right)_{\mathrm{n}}-{ }^{+} \mathrm{H}_{3} \mathrm{NCHRCO}_{2}{ }^{-} \stackrel{K_{\mathrm{V}}}{\rightleftarrows}\left(\mathrm{MnO}_{2}\right)_{\mathrm{n}}-\mathrm{H}_{2} \mathrm{NCHRCO}_{2}^{-}+\mathrm{H}^{+} \\
& \left(\mathrm{MnO}_{2}\right)_{\mathrm{n}}-\mathrm{H}_{2} \mathrm{NCHRCO}_{2}{ }^{-} \stackrel{k_{\mathrm{VI}}}{\text { slow }}\left(\mathrm{MnO}_{2}\right)_{\mathrm{n}-1}-\mathrm{MnO}+\mathrm{HN}=\mathrm{CHR}+\mathrm{CO}_{2}+\mathrm{HO}^{-}
\end{aligned}
$$

leading, by application of the quasi-equilibrium approximation, to the law:

$$
k_{2}=\frac{K_{\mathrm{IV}} K_{\mathrm{V}} k_{\mathrm{VI}}[\mathrm{L}-\mathrm{Phe}]_{\mathrm{T}}}{\left(1+K_{\mathrm{IV}}[\mathrm{L}-\mathrm{Phe}]_{\mathrm{T}}\right)\left(K_{\mathrm{V}}+\left[\mathrm{H}^{+}\right]\right)}
$$

Equation 27 is consistent with the independence of rate constant $k_{2}$ of the amino acid concentration provided that $K_{\mathrm{IV}}[\mathrm{L}-\mathrm{Phe}]_{\mathrm{T}} \gg 1$. This condition corresponds to saturation of the colloid surface by the amino acid. Actually, kinetic laws of zero order in the substrate are very frequent in surface reactions. ${ }^{74}$ Moreover, it is also consistent with the existence of $k_{2}$ versus $\left[\mathrm{H}^{+}\right]^{-1}$ linear plots (Figure 8, middle) provided that $K_{\mathrm{V}} \ll\left[\mathrm{H}^{+}\right]$, condition requiring that most 
of the amino acid fixed on the colloid surface being in the zwitterionic form. According to these approximations, eq 28 can be written as:

$$
k_{2}=\frac{K_{\mathrm{V}} k_{\mathrm{VI}}}{\left[\mathrm{H}^{+}\right]}
$$

Phosphate ions, used to buffer the solutions, are known to fix at the colloidal $\mathrm{MnO}_{2}$ surface, thus allowing that the negatively charged colloid particles be stable in solution for a long period. ${ }^{75}$ In the case of the permanganate/glycine reaction, an inhibition of the autocatalytic pathway with increasing phosphate concentration was found, ${ }^{65}$ thus suggesting that the $\mathrm{MnO}_{2}$-bound phosphate ions hinder the approach of the amino acid to the colloid surface.

The increase of the apparent activation energy associated to the experimental rate constant $k_{2}$ with increasing $\mathrm{pH}$ (Table 4) suggests that the composition of the colloid surface is strongly dependent on $\mathrm{pH}$, the basic form of the buffer $\left(\mathrm{HPO}_{4}{ }^{2-}\right)$ being a stronger inhibitor of the $\mathrm{Mn}(\mathrm{IV})$ reduction by L-phenylalanine than the acidic form $\left(\mathrm{H}_{2} \mathrm{PO}_{4}{ }^{-}\right)$. The corresponding increase of the activation entropy with increasing $\mathrm{pH}$ seems a consequence of the well-known compensation effect in chemical kinetics, since an increase in the activation enthalpy usually is correlated with an increase in the activation entropy. ${ }^{76}$

4.4. Mechanism Associated to Rate Constant $\boldsymbol{k}_{\mathbf{3}}$. The mechanism proposed for the last part of the autocatalytic reaction pathway is:

$$
\begin{aligned}
& \left(\mathrm{MnO}_{2}\right)_{\mathrm{n}-1}-\mathrm{MnO}+{ }^{+} \mathrm{H}_{3} \mathrm{NCHRCO}_{2}{ }^{-} \stackrel{K_{\mathrm{VII}}}{\rightleftarrows}\left(\mathrm{MnO}_{2}\right)_{\mathrm{n}-1}-\mathrm{MnO}-{ }^{+} \mathrm{H}_{3} \mathrm{NCHRCO}_{2}{ }^{-} \\
& \left(\mathrm{MnO}_{2}\right)_{\mathrm{n}-1}-\mathrm{MnO}-{ }^{+} \mathrm{H}_{3} \mathrm{NCHRCO}_{2}{ }^{-} \stackrel{K_{\mathrm{VIII}}}{\rightleftarrows}\left(\mathrm{MnO}_{2}\right)_{\mathrm{n}-1}-\mathrm{MnO}-\mathrm{H}_{2} \mathrm{NCHRCO}_{2}{ }^{-}+\mathrm{H}^{+}
\end{aligned}
$$




$$
\begin{aligned}
& \mathrm{MnO}_{4}{ }^{-}+\left(\mathrm{MnO}_{2}\right)_{\mathrm{n}-1}-\mathrm{MnO}-{ }^{+} \mathrm{H}_{3} \mathrm{NCHRCO}_{2}{ }^{-} \frac{k_{\mathrm{IX}}}{\text { slow }}\left(\mathrm{MnO}_{2}\right)_{\mathrm{n}+1}+\mathrm{H}_{2} \mathrm{NC}^{\cdot} \mathrm{RCO}_{2}{ }^{-}+\mathrm{H}_{2} \mathrm{O} \\
& \mathrm{MnO}_{4}{ }^{-}+\left(\mathrm{MnO}_{2}\right)_{\mathrm{n}-1}-\mathrm{MnO}-\mathrm{H}_{2} \mathrm{NCHRCO}_{2}{ }^{-} \frac{k_{\mathrm{X}}}{\text { slow }}\left(\mathrm{MnO}_{2}\right)_{\mathrm{n}+1}+\mathrm{H}_{2} \mathrm{NC}^{-} \mathrm{RCO}_{2}{ }^{-}+\mathrm{HO}^{-} \\
& \left(\mathrm{MnO}_{2}\right)_{\mathrm{n}-1}-\mathrm{MnO} \longrightarrow\left(\mathrm{MnO}_{2}\right)_{\mathrm{n}-2}-\mathrm{Mn}_{2} \mathrm{O}_{3}
\end{aligned}
$$

Application of the quasi-equilibrium approximation leads to the law:

$$
k_{3}=\frac{K_{\mathrm{VII}}\left(k_{\mathrm{IX}}\left[\mathrm{H}^{+}\right]+K_{\mathrm{VIII}} k_{\mathrm{X}}\right)[\mathrm{L}-\mathrm{Phe}]_{\mathrm{T}}}{K_{\mathrm{VIII}}+\left[\mathrm{H}^{+}\right]}
$$

which is consistent with base catalysis provided that $k_{\mathrm{X}}>k_{\mathrm{IX}}$, and with the existence of $k_{3}$ versus $\left[\mathrm{H}^{+}\right]^{-1}$ linear plots (Figure 8 , bottom) if $K_{\mathrm{VIII}}<<\left[\mathrm{H}^{+}\right]$, yielding:

$$
k_{3}=\left(k_{\mathrm{IX}}+\frac{K_{\mathrm{VIII}} k_{\mathrm{X}}}{\left[\mathrm{H}^{+}\right]}\right) K_{\mathrm{VII}}[\mathrm{L}-\mathrm{Phe}]_{\mathrm{T}}
$$

Thus, the intercepts of those plots are associated to the reaction on the colloid surface involving the zwitterionic form of the amino acid and the slopes to the reaction involving the anionic form.

Hence, according to eq 36 and the activation parameters given in Table 6, we can conclude that the slight decrease of the apparent activation energy associated to rate constant $k_{3}$ with increasing $\mathrm{pH}$ (Table 5) can be explained because the temperature dependence of rate constant $k_{\mathrm{IX}}\left(E_{\mathrm{a}, \mathrm{IX}}=79 \pm 2 \mathrm{~kJ} \mathrm{~mol}^{-1}\right)$ is little higher than that of the product $K_{\mathrm{VIII}} k_{\mathrm{X}}\left(\Delta H_{\mathrm{VIII}}^{\mathrm{o}}+E_{\mathrm{a}, \mathrm{X}}=\right.$ $70 \pm 1 \mathrm{~kJ} \mathrm{~mol}^{-1}$ ). The corresponding decrease of the activation entropy with increasing $\mathrm{pH}$ is again consistent with the kinetic enthalpy-entropy compensation effect. It should be noticed 
that the finding of negative values for the activation entropy associated to rate constant $k_{1}$ (Table 3) and of positive values for that associated to rate constant $k_{3}$ (Table 5) should not be interpreted in terms of a different degree of disorder in the structures of the corresponding transition states, since it has to be kept in mind that the activation entropies associated to rate constants with different units have a different dependence on the arbitrary choice of standard state. $^{77}$

Given that $\mathrm{Mn}(\mathrm{II})$ at low concentrations is transparent to the visible radiation, no direct experimental evidence of its formation has been found. Under the conditions of this work, it is expected to disappear by two competing reactions: oxidation by permanganate ion (eqs 32 and 33) and comproportionation with Mn(IV) to yield Mn(III) (eq 34).

4.5. Hydrolysis of the Organic Free Radical. It has been assumed in the proposed mechanism that a hydrogen atom is transferred from the $\alpha$ position of the amino acid to permanganate ion, leading to a resonance-stabilized organic free radical (eqs 14 and 15). This process is energetically favored over the transfer of an electron from either the carboxylate (zwitterionic/anionic forms) or the amino (anionic form) groups, as well as over the transfer of a hydrogen atom from either the ammonium (zwitterionic form) or the amino (anionic form) groups of L-phenylalanine. This is so because the organic radical formed in eqs 14 and 15 has its unpaired electron delocalized over a wider region than the other free radicals that could be potentially formed in the permanganate/amino acid reaction. The problem with this proposal, however, is that the hydrogen atom in the $\alpha$ position of the organic substrate is required for the formation of the aldehyde experimentally observed. This has been resolved with the hydrolysis of the organic free radical proposed in eq 16, in which a hydrogen atom in the required position is recuperated from the solvent as illustrated in the concerted electronjump process shown in Scheme 2.

\section{Scheme 2}


4.6. Dismutation of Manganese Species. One-electron redox processes have been favored over two-electron redox processes to initiate the reaction (eqs 14 and 15) because it is known that the permanganate oxidations of organic compounds in alkaline media yield $\mathrm{Mn}(\mathrm{VI}){ }^{78}$ This seems to suggest as a general rule that most of those reactions start with the reduction $\mathrm{Mn}(\mathrm{VII}) \longrightarrow \mathrm{Mn}(\mathrm{VI})$, and that lower oxidation states are formed from dismutation of $\mathrm{Mn}(\mathrm{VI})$ (eq 20) if the $\mathrm{pH}$ is low enough. The dismutation of $\mathrm{Mn}(\mathrm{VI})$ to yield $\mathrm{Mn}(\mathrm{VII})$ and $\mathrm{Mn}(\mathrm{V})$ (eq 20) has been assumed to involve hydrogenmanganate ion $\left(\mathrm{HMnO}_{4}{ }^{-}\right)$as the oxidizing species and manganate ion $\left(\mathrm{MnO}_{4}{ }^{2-}\right)$ as the reducing one. This is coherent with the known fact that $\mathrm{Mn}(\mathrm{VI})$ is stable at high $\mathrm{pH}$ (because the concentration of $\mathrm{HMnO}_{4}{ }^{-}$is too low) but dismutates at lower $\mathrm{pH}$. It is also coherent with the evidence that a low electronic density species as $\mathrm{HMnO}_{4}{ }^{-}$is a good candidate to act as oxidant whereas a high electronic density species as $\mathrm{MnO}_{4}{ }^{2-}$ is expected to be a good candidate to act as reductant. For instance, in the nonenzymatic dismutation of superoxide radicals the rate constant for the $\mathrm{HO}_{2} \cdot / \mathrm{O}_{2}{ }^{--}$reaction is much higher than those for the $\mathrm{HO}_{2} \cdot / \mathrm{HO}_{2}{ }^{\cdot}$ and $\mathrm{O}_{2}{ }^{-{ }^{-}} / \mathrm{O}_{2}{ }^{--}$reactions, ${ }^{79}$ since the low electronic density species $\mathrm{HO}_{2}{ }^{\cdot}$ acts as oxidant and the high electronic density species $\mathrm{O}_{2}{ }^{--}$ as reductant. Additional support can be found in the known fact that $\mathrm{Mn}$ (III) is stable at low $\mathrm{pH}$ and (in the absence of stabilizing ligands as fluoride or pyrophosphate ions) dismutates at high $\mathrm{pH}^{80}$ just the opposite of the behavior of $\mathrm{Mn}(\mathrm{VI})$. It seems that the dismutation of $\mathrm{Mn}(\mathrm{III})$ might involve preferentially a $\mathrm{Mn}^{3+} /[\mathrm{Mn}(\mathrm{OH})]^{2+}$ reaction, the low electronic density species $\mathrm{Mn}^{3+}$ acting as oxidant and the high electronic density species $[\mathrm{Mn}(\mathrm{OH})]^{2+}$ as reductant. This different $\mathrm{pH}$ behavior of the dismutations of $\mathrm{Mn}(\mathrm{VI})$ and $\mathrm{Mn}(\mathrm{III})$ might thus have its origin in the anionic nature of the former and the cationic nature of the latter. 


\section{$\square$ ASSOCIATED CONTENT}

\section{s Supporting Information}

BASIC-language computer program for the determination of three experimental rate constants for permanganate reactions autocatalyzed by colloidal manganese dioxide from the absorbances at both 420 and $525 \mathrm{~nm}$ measured periodically during the kinetic runs. This material is available free of charge via the Internet at http://pubs.acs.org.

\section{AUTHOR INFORMATION}

\section{Corresponding Author}

* E-mail: jfperezdebenito@ub.edu.

\section{REFERENCES}

(1) Freeman, F. Postulated Intermediates and Activated Complexes in the Permanganate Ion Oxidation of Organic Compounds. Rev. React. Species Chem. React. 1976, 1, 179-226

(2) Fatiadi, A. J. The Classical Permanganate Ion - Still a Novel Oxidant in Organic Chemistry. Synthesis. 1987, 85-127.

(3) Singh, N.; Lee, D. G. Permanganate: A Green and Versatile Industrial Oxidant. Org. Process Res. Dev. 2001, 5, 599-603.

(4) Kint, C.; Verstraeten, N.; Hofkens, J.; Fauvart, M.; Michiels, J. Bacterial Obg Proteins: GTPases at the Nexus of Protein and DNA Synthesis. Crit. Rev. Microbiol. 2014, $40,207-224$ 
(5) Wolff, S. P.; Garner, A.; Dean, R. T. Free Radicals, Lipids and Protein Degradation. Trends Biochem. Sci. 1986, 11, 27-31.

(6) Ameta, S. C.; Pande, P. N.; Gupta, H. L.; Chowdhry, H. C. Kinetics of Oxidative Decarboxylation of L-Serine by Potassium Permanganate. Acta Phys. Chem. 1980, 26, $89-92$.

(7) Ameta, S. C.; Gupta, H. L.; Pande, P. N.; Chowdhry, H. C. Kinetics of Oxidative Decarboxylation of DL-Aspartic Acid by Potassium Permanganate. Z. Phys. Chem. Leipzig 1980, 261, $802-804$.

(8) Ameta, S. C.; Pande, P. N.; Gupta, H. L.; Chowdhry, H. C. Kinetic-Study of Oxidative Decarboxylation of L-Beta-Phenylalanine by Potassium-Permanganate. Z. Phys. Chem. Leipzig 1980, 261, $1222-1224$.

(9) Ameta, S. C.; Pande, P. N.; Gupta, H. L.; Chowdhry, H. C. Kinetics of Oxidative Decarboxylation of L-Cysteine by Permanganate. Acta Chim. Academ. Sci. Hung. 1982, 110, $7-11$.

(10) Hassan, R. M.; Mousa, M. A.; Wahdan, M. H. Kinetics and Mechanism of Oxidation of Beta-Phenylalanine by Permanganate Ion in Aqueous Perchloric Acid. J. Chem. Soc., Dalton Trans. 1988, 605-609.

(11) Andres-Ordax, F. J.; Arrizabalaga, A.; Peche, R.; Quintana, M. A. Kinetic Study of Autocatalytic Oxidation of L Alanine by Potassium Permanganate in Acidic Medium pH 1-3. An. Quim. 1991, 87, 828-832.

(12) Andres-Ordax, F. J.; Arrizabalaga, A.; Casado, J.; Peche, R. Kinetic Study of the Oxidation of L-Threonine by $\mathrm{MnO}_{4}{ }^{-}$Ions. React. Kinet. Catal. Lett. 1991, 44, $293-301$.

(13) Hassan, R. M. Kinetics and Mechanism of Oxidation of DL- $\alpha$-Alanine by Permanganate Ion in Acid Perchlorate Media. Can. J. Chem. 1991, 69, 2018 -2023. 
(14) Andres-Ordax, F. J.; Arrizabalaga, A.; Casado, J.; Peche, R.; Quintana, M. A. Kinetic Study of the Autocatalytic Oxidation of Glycine by the Permanganate Ions in Acid Medium (pH 1-3). An. Quim. 1992, 88, 440-443.

(15) Insausti, M. J.; Mata-Perez, F.; Alvarez-Macho, M. P. Permanganate Oxidation of LAlanine in Acidic Solvent-Autocatalysis by Intermediate Mn(IV) Species. Collect. Czech. Chem. Commun. 1994, 59, 528-538.

(16) Insausti, M. J.; Mata-Perez, F.; Alvarez-Macho, M. P. Kinetic-Study of the Oxidation of L-Phenylalanine by Potassium-Permanganate in Acid Medium. Int. J. Chem. Kinet. 1995, $27,507-515$

(17) Insausti, M. J.; Mata-Perez, F.; Alvarez-Macho, M. P. Kinetic Study of the Oxidation of Glycine by Permanganate Ions in Acid Medium. Collect. Czech. Chem. Commun. 1996, 61, 232-241.

(18) Arrizabalaga, A.; Andres-Ordax, F. J.; Fernandez-Aranguiz, M. Y.; Peche, R. Kinetics and Mechanism of the oxidation of L- $\alpha$-Aminobutyric Acid by Permanganate in Acid Medium. Int. J. Chem. Kinet. 1996, 28, 799-805.

(19) Iloukhani, H.; Bahrami, H. Kinetic Studies and Mechanism on the Permanganic Oxidation of L-Glutamine in Strong Acid Medium in the Presence and Absence of Silver(I). Int. J. Chem. Kinet. 1999, 31, 95-102.

(20) Iloukhani, H.; Moazenzadeh, M. Thermodynamic and Kinetic Studies of Oxidation of L-Histidine by Manganese(VII) in Concentrated Sulfuric Acid Medium in the Absence and Presence of Silver(I). Phys. Chem. Liq. 2001, 39, 429-442.

(21) Khan, F. H.; Ahmad, F. Micellar Effect on Two-Phase Kinetics of Oxidative Degradation of Lysine. Oxid. Commun. 2004, 27, 869-885. 
(22) Bahrami, H.; Zahedi, M. Kinetics and Mechanism of the Oxidation of L- $\alpha$ Aminobutyric Acid in Moderately Concentrated Sulfuric Acid Medium. Can. J. Chem. 2004, $82,430-436$.

(23) Zahedi, M.; Bahrami, H. Kinetics and Mechanism of the Autocatalytic Oxidation of L-Asparagine in a Moderately Concentrated Sulfuric Acid Medium. Kinet. Catal. 2004, 45, $351-358$

(24) Fawzy, A.; Ashour, S. S.; Musleh, M. A. Kinetics and Mechanism of Oxidation of LHistidine by Permanganate Ions in Sulfuric Acid Medium. Int. J. Chem. Kinet. 2014, 46, $370-381$

(25) Andres-Ordax, F. J.; Arrizabalaga, A.; Martinez, J. I. Kinetic-Study of the Oxidation of L-Phenylalanine by Potassium-Permanganate in Neutral Medium. An. Quim. 1984, 80, $531-535$.

(26) Garrido, J. A.; Perez-Benito, J. F.; Rodríguez, R. M.; De Andres, J.; Brillas, E. Autocatalysis by Colloidal Manganese Dioxide in the Permanganate Oxidation of LIsoleucine. J. Chem. Res. (S) 1987, 380-381.

(27) Brillas, E.; Garrido, J. A.; Perez-Benito, J. F.; Rodríguez, R. M.; De Andres, J. Kinetic Study of Permanganate Oxidation of L-Leucine in Neutral Aqueous Solution. Collect. Czech. Chem. Commun. 1988, 53, 479-486.

(28) De Andres, J.; Brillas, E.; Garrido, J. A.; Perez-Benito, J. F.; Rodríguez, R. M. The Reaction Between L-Glutamic Acid and Permanganate Ion in Neutral Aqueous Solutions. Gazz. Chim. Ital. 1988, 118, $203-207$.

(29) De Andres, J.; Brillas, E.; Garrido, J. A.; Perez-Benito, J. F. Kinetics and Mechanisms of the Oxidation by Permanganate of L-Alanine. J. Chem. Soc., Perkin Trans. 2. 1988, $107-112$ 
(30) Rodríguez, R. M.; De Andres, J.; Brillas, E.; Garrido, J. A.; Perez-Benito, J. F. Autocatalytic Permanganate Oxidation of L-Threonine. New. J. Chem. 1988, 12, 143 - 146.

(31) Andres-Ordax, F. J.; Arrizabalaga, A.; Ortega, K. Kinetic Chemical Studies in Autocatalytic Systems - Oxidations of L-Serine by Permanganate Ions. An. Quim. 1989, 85, $218-223$.

(32) Perez-Benito, J. F.; Rodríguez, R. M.; De Andres, J.; Brillas, E.; Garrido, J. A. Kinetics and Mechanisms of the Permanganate Oxidation of L-Valine in Neutral Aqueous Solutions. Int. J. Chem. Kinet. 1989, 21, $71-81$.

(33) Insausti, M. J.; Mata-Perez, F.; Alvarez-Macho, M. P. Analysis of the Rate-Time Profiles for the Permanganic Oxidation of Glycine. An. Quim. 1990, 86, 710-714.

(34) Insausti, M. J.; Mata-Perez, F.; Alvarez-Macho, M. P. Permanganate Ion Oxidation of Glycine. An. Quim. 1991, 87, 821-827.

(35) Insausti, M. J.; Mata-Perez, F.; Alvarez-Macho, M. P. Kinetic-Study of the Permanganate Oxidation of L-Alanine. An. Quim. 1991, 87, 877-883.

(36) Insausti, M. J.; Mata-Perez, F.; Alvarez-Macho, M. P. Kinetics and Mechanisms of the Oxidation by Permanganate of L-Phenylalanine. Int. J. Chem. Kinet. 1991, 23, 593-605.

(37) Insausti, M. J.; Mata-Perez, F.; Alvarez-Macho, M. P. Oxidation of $\alpha$-Amino Acids by Permanganate - Isokinetic Relation. Collect. Czech. Chem. Commun. 1992, 57, $2331-2336$.

(38) Insausti, M. J.; Mata-Perez, F.; Alvarez-Macho, M. P. Permanganate Oxidation of Glycine - Influence of Amino Acid on Colloidal Manganese Dioxide. Int. J. Chem. Kinet. 1992, 24, $411-419$.

(39) Insausti, M. J.; Mata-Perez, F.; Alvarez-Macho, M. P. UV-Vis Spectrophotometric Study and Dynamic Analysis of the Colloidal Product of Permanganate Oxidation of $\alpha$ Amino Acids. Kinet. Catal. Lett. 1993, 51, 51-59. 
(40) Malik, M. A.; Khan, Z. Role of Cetyltrimethylammonium Bromide (Cationic Surfactant) on the Tryptophan- $\mathrm{MnO}_{4}{ }^{-}$Reaction. Colloids Surf. B 2009, 72, $253-258$.

(41) Perez-Benito, J. F. Permanganate Oxidation of $\alpha$-Amino Acids: Kinetic Correlations for the Nonautocatalytic and Autocatalytic Reaction Pathways. J. Phys. Chem. A 2011, 115, $9876-9885$.

(42) Andres-Ordax, F. J.; Aririzabalaga, A. The Induction Period in Autocatalytic Reactions. Treatment of Kinetic Data. An. Quim. 1985, 81, 431-433.

(43) Mata-Perez, F.; Perez-Benito, J. F. The Kinetic Rate Law for Autocatalytic Reactions. J. Chem. Educ. 1987, 64, 925 - 927.

(44) Perez-Benito, J. F.; Arias, C.; Brillas, E. Kinetic Treatment of Autocatalytic Reactions. An. Quim. 1991, 87, 849-852.

(45) Perez-Benito, J. F. Autocatalytic Reaction Pathway on Manganese Dioxide Colloidal Particles in the Permanganate Oxidation of Glycine. J. Phys. Chem. C 2009, 113, $15982-15991$

(46) Bahrami, H.; Zahedi, M. Delayed Autocatalytic Behavior of Mn(II) Ions at a Critical Ratio: The Effect of Structural Isomerism on Permanganic Oxidation of L-Norleucine. Int. J. Chem. Kinet. 2006, 38, 1-11.

(47) Bahrami, H.; Zahedi, M. Conclusive Evidence for Delayed Autocatalytic Behavior of Mn(II) Ions at a Critical Concentration. J. Iran. Chem. Soc. 2008, 5, 535-545.

(48) Khatti, Z.; Davari, M. D.; Bahrami, H.; Zahedi, M. Kinetics and Mechanism of the Permanganate-Induced Oxidative Catalytic Condensation of Sarcosine to a Diketopiperazine. Prog. React. Kinet. Mech. 2010, 35, 1-26.

(49) Davari, M. D.; Bahrami, H.; Zahedi, M.; Jadidi, K. Kinetics and Mechanism of the $\mathrm{KMnO}_{4}$-Oxidative Catalysed Condensation Reaction of L-Proline to a Diketopiperazine: Evidence for Delayed Autocatalytic Behaviour. Prog. React. Kinet. Mech. 2011, 36, 95-119. 
(50) Bahrami, H.; Bigdeli, M.; Davari, M. D.; Zahedi, M.; Moosavi-Movahedi, A. A. Kinetics and Mechanism of the Permanganate-Induced Autocatalytic Dehydration Reaction of L- $\gamma$-Aminobutyric Acid to Give 2-Pyrrolidone through a Radical Intermediate in Moderately Concentrated Acidic Medium. Prog. React. Kinet. Mech. 2011, 36, 120 -138.

(51) Perez-Benito, J. F. The Singular Autocatalytic Behaviour of the Oxidation of Acetic Acid by Methyltributylammonium Permanganate in Methylene Chloride. J. Chem. Soc., Chem. Commun. 1987, $831-833$.

(52) Perez-Benito, J. F.; Arias, C.; Lamrhari, D.; Anhari, A. The Determination of Kinetic Data for the Reactions of Chromium(VI) with Glutathione and Other Thiols. Int. J. Chem. Kinet. 1994, 26, 587-591.

(53) Perez-Benito, J. F.; Lamrhari, D.; Arias, C. Three Rate Constants from a Single Kinetic Experiment: Formation, Decomposition, and Reactivity of the Chromium(VI) - Glutathione Thioester Intermediate. J. Phys. Chem. 1994, 98, 12621 - 12629. (54) Ramachandran, B. R.; Halpern, A. M. A Novel Experiment in Chemical Kinetics: The $\mathrm{A} \rightleftarrows \mathrm{B} \longrightarrow \mathrm{C}$ Reaction System. J. Chem. Educ. 1997, 74, 975-978.

(55) Perez-Benito, J. F.; Saiz, N.; Amat, E. Catalysis by Zinc Ion in the Reactions of Carcinogenic Chromium(VI) with Thiols. J. Mol. Catal. A 1998, 135, 1 - 10.

(56) Khan, Z.; Al-Thabaiti, S. A.; Obaid, A. Y.; Khan, Z. A. $\mathrm{MnO}_{2}$ Nanostructures of Different Morphologies from Amino Acids- $\mathrm{MnO}_{4}{ }^{-}$Reactions in Aqueous Solutions. Colloids Surf. B 2010, 81, $381-384$.

(57) Perez-Benito, J. F.; Arias, C. Occurrence of Colloidal Manganese Dioxide in Permanganate Reactions. J. Colloid Interface Sci. 1992, 152, 70 -84.

(58) Wells, C. F.; Davies, G. A Spectrophotometric Investigation of the Aquomanganese(III) Ion in Perchlorate Media. J. Chem. Soc. A 1967, $1858-1861$. 
(59) Jaky, M.; Simandi, L. I. Mechanism of the Permanganate Oxidation of Unsaturated Compounds. Part I. Short-lived Intermediates of the Oxidation of Acetylenedicarboxylic Acid. J. Chem. Soc., Perkin Trans. 2 1972, $1481-1486$.

(60) Adamcikova, L.; Krizova, A.; Valent, I. Kinetics of the Manganese(III)-Oxalate Reaction in Acidic Sulphate Media. Transition Met. Chem. 1993, 18, $218-220$.

(61) Al-Thabaiti, S. A.; Al-Nowaiser, F. M.; Obaid, A. Y.; Al-Youbi, A. O.; Khan, Z. Formation and Decomposition of Water Soluble Colloidal Manganese Dioxide During the Reduction of $\mathrm{MnO}_{4}^{-}$by Cysteine. A Kinetic Study. J. Dispers. Sci. Technol. 2008, 29, $1391-1395$.

(62) Kabir-ud-Din; Altaf, M.; Akram, M. The Kinetics of Oxidation of L-Tryptophan by Water-Soluble Colloidal Manganese Dioxide. J. Dispers. Sci. Technol. 2008, 29, 809-816.

(63) Altaf, M.; Akram, M.; Kabir-ud-Din. Water-Soluble Colloidal Manganese Dioxide as an Oxidant for L-Tyrosine in the Absence and Presence of Non-Ionic Surfactant TX-100. Colloids Surf. B 2009, 73, $308-314$.

(64) Espenson, J. H. Chemical Kinetics and Reaction Mechanisms; McGraw-Hill: New York, 1995; p 379.

(65) Perez-Benito, J. F.; Mata-Perez, F.; Brillas, E. Permanganate Oxidation of Glycine: Kinetics, Catalytic Effects, and Mechanisms. Can. J. Chem. 1987, 65, 2329-2337.

(66) Perez-Benito, J. F.; Arias, C.; Amat, E. A Kinetic Study of the Reduction of Colloidal Manganese Dioxide by Oxalic Acid. J. Colloid Interface Sci. 1996, 177, 288-297. (67) Zaheer, Z.; Rafiuddin. Sub- and Post-Micellar Catalytic and Inhibitory Effects of Cetyltrimethylammonium Bromide in the Permanganate Oxidation of Phenylalanine. Colloids Surf. B 2009, 69, 251-256.

(68) Pratihar, S. Electrophilicity and Nucleophilicity of Commonly Used Aldehydes. Org. Biomol. Chem. 2014, 12, 5781-5788. 
(69) Bajpai, U. D. N.; Bajpai, A. K. Aqueous Polymerization of Acrylamide Initiated with the Permanganate- L-Serine Redox System. Macromolecules 1985, 18, 2113 -2116.

(70) Perez-Benito, J. F.; Arias, C. A Kinetic Study of the Permanganate Oxidation of Triethylamine. Catalysis by Soluble Colloids. Int. J. Chem. Kinet. 1991, 23, 717-732.

(71) Wei, M. M.; Stewart, R. The Mechanisms of Permanganate Oxidation. VIII. Substituted Benzylamines. J. Am. Chem. Soc. 1966, 88, 1974-1979.

(72) Galwey, A. K.; Fakiha, S. A. A.; Abd El-Salaam, K. M. A Kinetic and Mechanistic Study of the Thermal Decomposition of Nickel Permanganate. Termochim. Acta 1992, 206, $297-307$.

(73) Coetzee, J. F.; Ritchie, C. D. Solute-Solvent Interactions; Dekker: New York, 1969; p 17.

(74) McCabe, R. W. Kinetics of Ammonia Decomposition on Nickel. J. Catal. 1983, 79, $445-450$.

(75) Mata-Perez, F.; Perez-Benito, J. F. Identification of the Product from the Reduction of Permanganate Ion by Trimethylamine in Aqueous Phosphate Buffers. Can. J. Chem. 1985, $63,988-992$.

(76) Perez-Benito, J. F. Some Tentative Explanations for the Enthalpy-Entropy Compensation Effect in Chemical Kinetics: from Experimental Errors to the HinshelwoodLike Model. Monatsh. Chem. 2013, 144, $49-58$.

(77) Robinson, P. J. Dimensions and Standard States in the Activated Complex Theory of Reaction Rates. J. Chem. Educ. 1978, 55, 509-510.

(78) Lee, D. G.; Nagarajan, K. Oxidation of Hydrocarbons. 13. The Oxidation of Cinnamate Ion by Alkaline Permanganate. Can. J. Chem. 1985, 63, 1018-1023.

(79) Sawyer, D. T.; Valentine, J. S. How Super is Superoxide?. Acc. Chem. Res. 1981, 14, $393-400$. 
(80) Stewart, R. In Oxidation in Organic Chemistry; Wiberg, K. B., Ed.; Academic Press: New York, 1965; p 8. 
Scheme 1. Simplified Mechanism Showing the Role of the Three Experimental Rate Constants

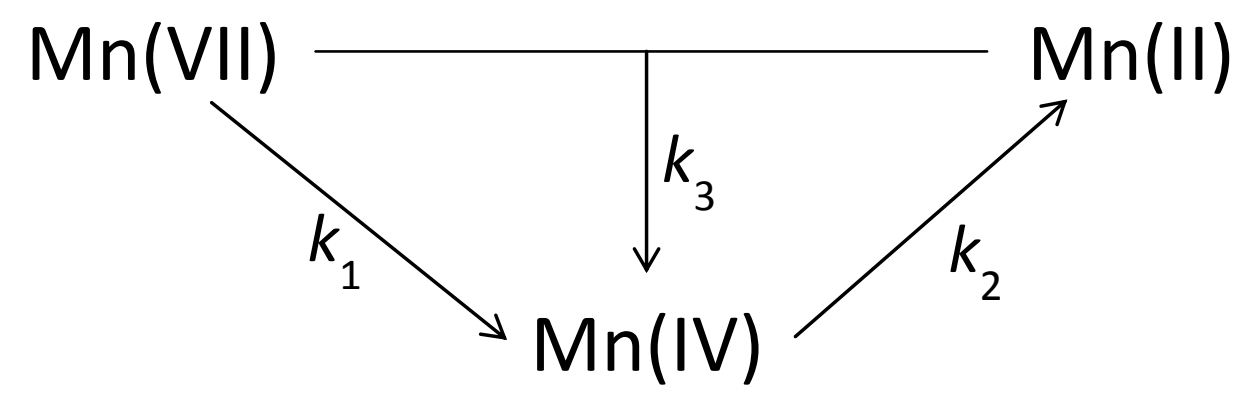


Scheme 2. Concerted Two-Electron-Jump Process Proposed for the Hydrolysis of the Organic Free Radical

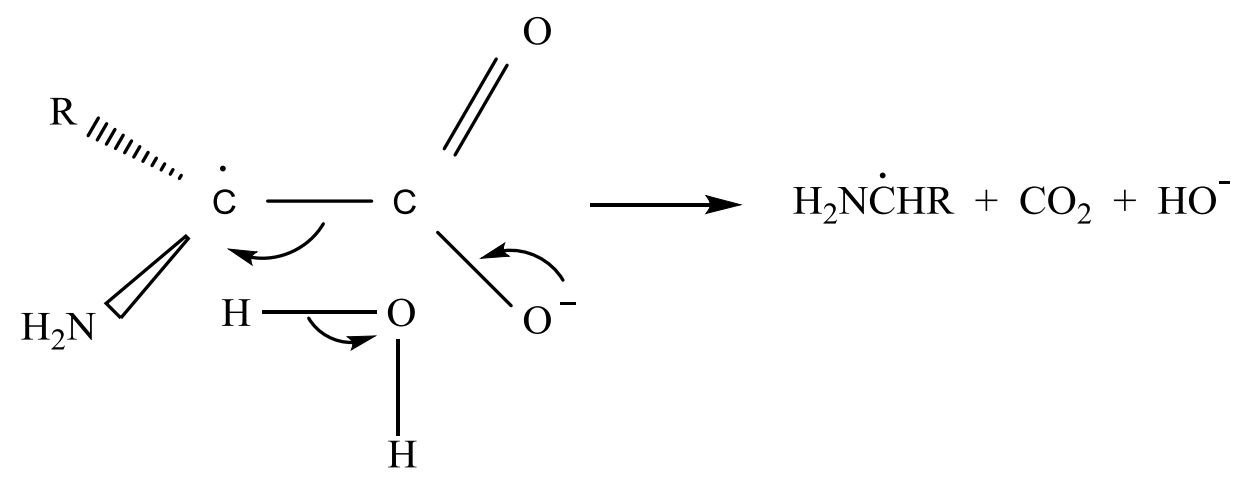


Table 1. Experimental Rate Constants at Different Initial Permanganate Concentrations $^{a, b}$

\begin{tabular}{cccc}
{$\left[\mathrm{KMnO}_{4}\right]_{\mathrm{o}} / 10^{-3} \mathrm{M}$} & $k_{1} / 10^{-5} \mathrm{~s}^{-1}$ & $k_{2} / 10^{-4} \mathrm{~s}^{-1}$ & $k_{3} / \mathrm{M}^{-1} \mathrm{~s}^{-1}$ \\
& & & \\
\hline 0.200 & $3.59 \pm 0.21$ & $0.71 \pm 0.14$ & $1.289 \pm 0.048$ \\
0.400 & $2.87 \pm 0.05$ & $3.61 \pm 0.12$ & $0.439 \pm 0.009$ \\
0.600 & $2.43 \pm 0.04$ & $10.02 \pm 1.00$ & $0.296 \pm 0.011$ \\
0.800 & $2.22 \pm 0.05$ & $10.59 \pm 0.27$ & $0.218 \pm 0.004$ \\
1.000 & & & $0.200 \pm 0.003$
\end{tabular}

${ }^{a}[\mathrm{~L}-\mathrm{Phenylalanine}]=5.00 \times 10^{-3} \mathrm{M},\left[\mathrm{KH}_{2} \mathrm{PO}_{4}\right]=0.120 \mathrm{M},\left[\mathrm{K}_{2} \mathrm{HPO}_{4}\right]=0.150 \mathrm{M}, \mathrm{pH} 6.826 \pm$ 0.004, $25.0{ }^{\circ} \mathrm{C} .{ }^{b}$ Errors associated to the rate constants were calculated as one half of the range (2 determinations). 
Table 2. Experimental Rate Constants at Different Potassium Chloride Concentrations $^{a, b}$

$[\mathrm{KCl}] / \mathrm{M} \quad \mathrm{pH} \quad k_{1} / 10^{-5} \mathrm{~s}^{-1} \quad k_{2} / 10^{-4} \mathrm{~s}^{-1} \quad k_{3} / \mathrm{M}^{-1} \mathrm{~s}^{-1}$

\begin{tabular}{lllll}
\hline 0.000 & $6.826 \pm 0.004$ & $3.31 \pm 0.05$ & $3.61 \pm 0.12$ & $0.439 \pm 0.009$ \\
0.120 & $6.786 \pm 0.002$ & $3.89 \pm 0.12$ & $1.58 \pm 0.24$ & $0.586 \pm 0.063$ \\
0.240 & $6.745 \pm 0.002$ & $4.03 \pm 0.01$ & $1.40 \pm 0.12$ & $0.522 \pm 0.040$ \\
0.360 & $6.718 \pm 0.001$ & $4.10 \pm 0.06$ & $1.36 \pm 0.21$ & $0.510 \pm 0.069$ \\
0.480 & $6.689 \pm 0.001$ & $4.29 \pm 0.04$ & $1.00 \pm 0.04$ & $0.535 \pm 0.005$
\end{tabular}

${ }^{a}\left[\mathrm{KMnO}_{4}\right]_{\mathrm{o}}=4.00 \times 10^{-4} \mathrm{M},[\mathrm{L}-\mathrm{Phenylalanine}]=5.00 \times 10^{-3} \mathrm{M},\left[\mathrm{KH}_{2} \mathrm{PO}_{4}\right]=0.120 \mathrm{M}$, $\left[\mathrm{K}_{2} \mathrm{HPO}_{4}\right]=0.150 \mathrm{M}, 25.0^{\circ} \mathrm{C} .{ }^{b}$ Errors associated to the $\mathrm{pH}$ and to the rate constants were calculated as one half of the range (2 determinations). 
Table 3. Apparent Activation Parameters Associated to Rate Constant $k_{1}$ at Different pH Values ${ }^{a, b, c}$

$\mathrm{pH} \quad E_{\mathrm{a}} / \mathrm{kJ} \mathrm{mol}^{-1} \quad \Delta H_{\neq}^{\mathrm{o}} / \mathrm{kJ} \mathrm{mol}^{-1} \quad \Delta S_{\neq}^{\mathrm{o}} / \mathrm{J} \mathrm{K}^{-1} \mathrm{~mol}^{-1}$

$\begin{array}{llll}6.655 \pm 0.009 & 68.7 \pm 1.3 & 66.2 \pm 1.3 & -68 \pm 4 \\ 6.826 \pm 0.004 & 70.9 \pm 0.8 & 68.4 \pm 0.8 & -57 \pm 3 \\ 7.021 \pm 0.004 & 65.9 \pm 1.5 & 63.4 \pm 1.5 & -71 \pm 5 \\ 7.229 \pm 0.006 & 70.1 \pm 0.5 & 67.6 \pm 0.5 & -55 \pm 2 \\ 7.471 \pm 0.007 & 67.8 \pm 1.3 & 65.3 \pm 1.3 & -60 \pm 4\end{array}$

${ }^{a}\left[\mathrm{KMnO}_{4}\right]_{\mathrm{O}}=4.00 \times 10^{-4} \mathrm{M},[\mathrm{L}-\mathrm{Phenylalanine}]=5.00 \times 10^{-3} \mathrm{M},\left[\mathrm{KH}_{2} \mathrm{PO}_{4}\right]=4.80 \times 10^{-}$ ${ }^{2}-0.144 \mathrm{M},\left[\mathrm{K}_{2} \mathrm{HPO}_{4}\right]=0.120-0.240 \mathrm{M}, 20.0-40.0{ }^{\circ} \mathrm{C} .{ }^{b}$ Errors associated to the $\mathrm{pH}$ values are standard deviations (10 determinations). ${ }^{c}$ Errors associated to the activation parameters were calculated from the standard deviations for the intercept and slope of the Arrhenius and Eyring plots. 
Table 4. Apparent Activation Parameters Associated to Rate Constant $k_{2}$ at Different pH Values ${ }^{a, b, c}$

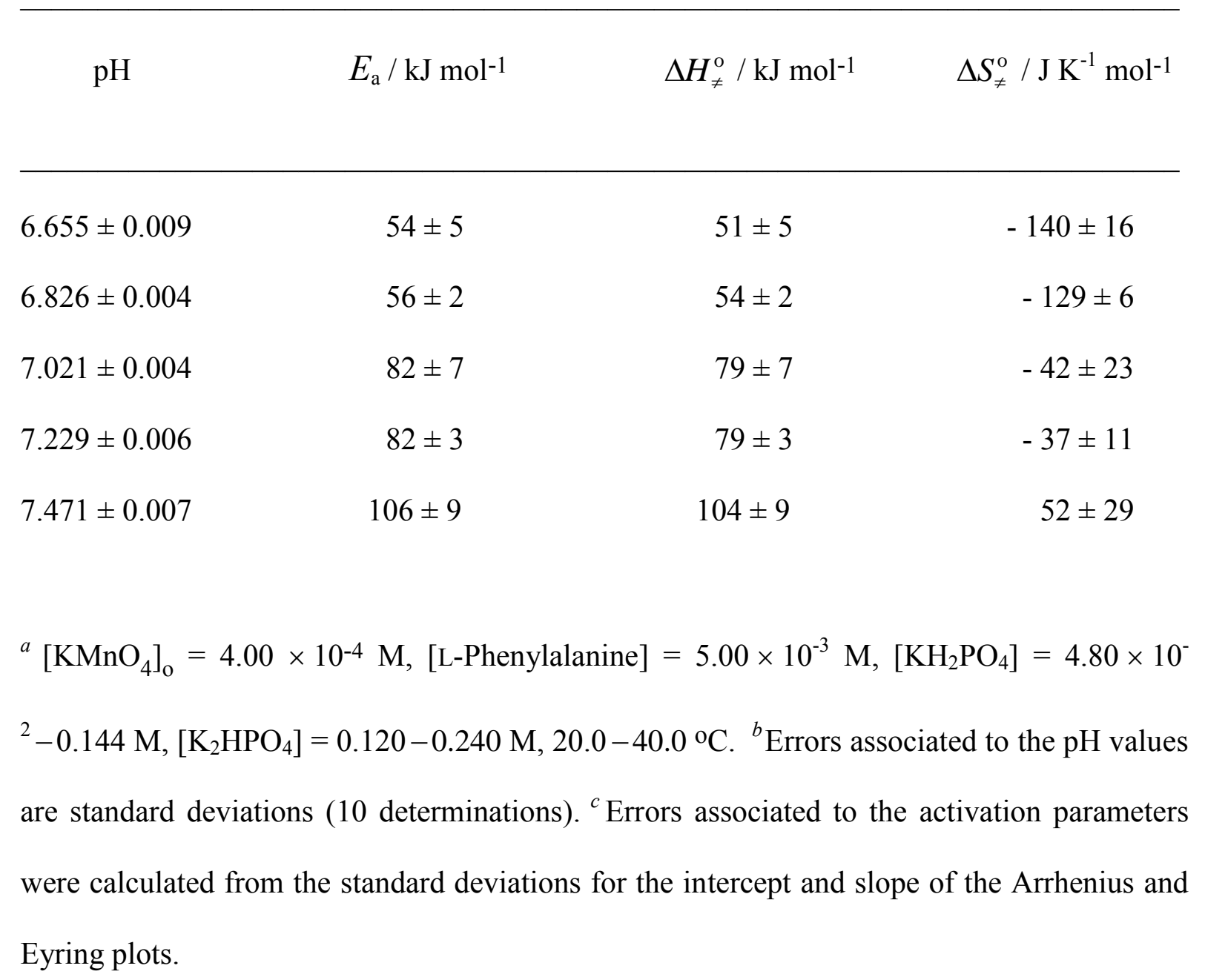


Table 5. Apparent Activation Parameters Associated to Rate Constant $k_{3}$ at Different pH Values ${ }^{a, b, c}$

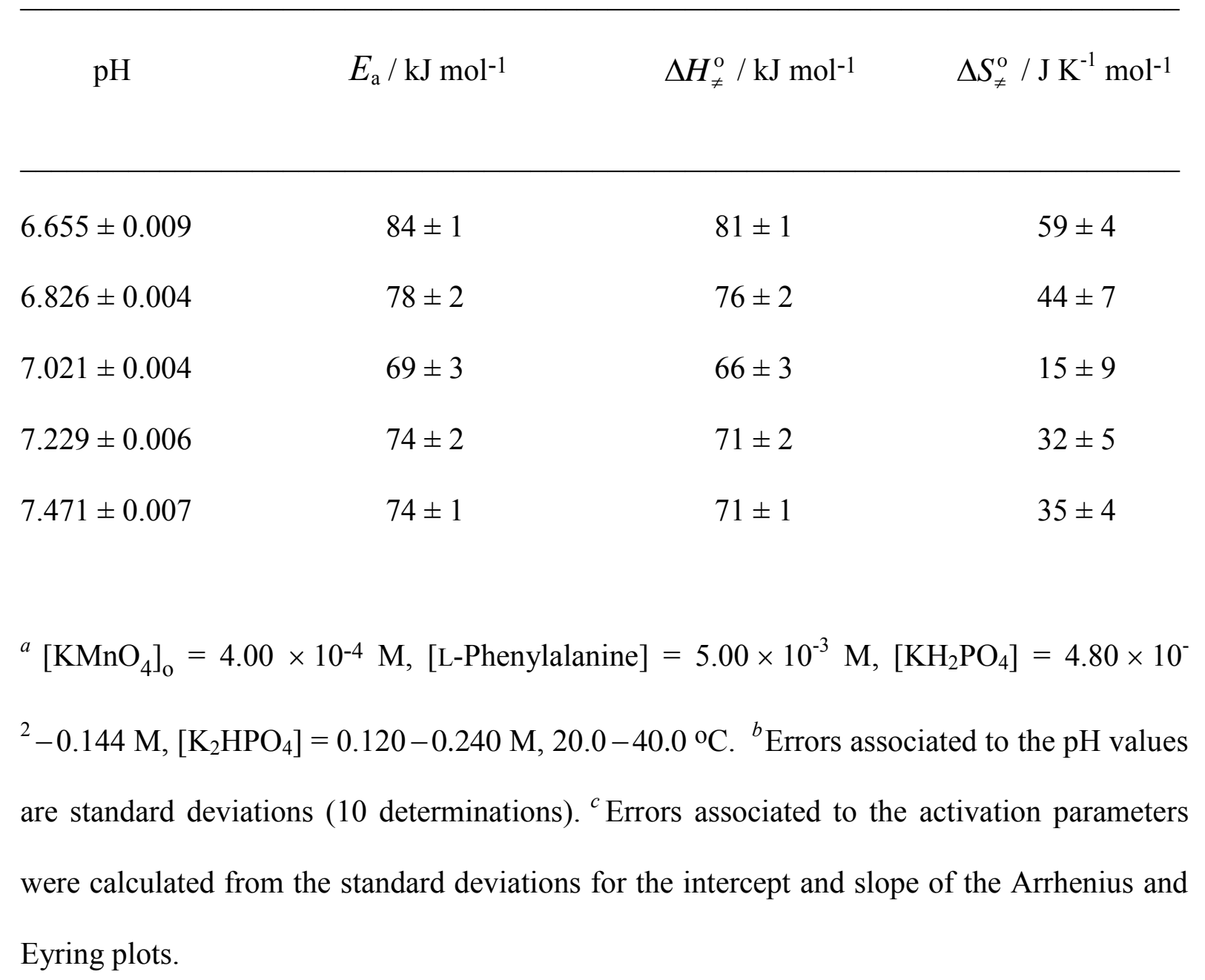


Table 6. pH-Independent Activation Parameters Associated to the Experimental Rate Constants $^{a, b, c}$

magnitude

$E_{\mathrm{a}} / \mathrm{kJ} \mathrm{mol}^{-1}$

$\Delta H_{\neq}^{\mathrm{o}} / \mathrm{kJ} \mathrm{mol}^{-1}$

$\Delta S_{\neq}^{\mathrm{o}} / \mathrm{J} \mathrm{K}^{-1} \mathrm{~mol}^{-1}$

$\begin{array}{lrrr}\text { intercept }\left(k_{1}\right) & 70 \pm 2 & 68 \pm 2 & -65 \pm 5 \\ \text { slope }\left(k_{1}\right) & 68 \pm 2 & 65 \pm 2 & -205 \pm 6 \\ \text { slope }\left(k_{2}\right) & 114 \pm 10 & 111 \pm 10 & -66 \pm 34 \\ \text { intercept }\left(k_{3}\right) & 79 \pm 2 & 76 \pm 2 & 42 \pm 5 \\ \text { slope }\left(k_{3}\right) & 70 \pm 1 & 68 \pm 1 & -122 \pm 5\end{array}$

${ }^{a}\left[\mathrm{KMnO}_{4}\right]_{\mathrm{O}}=4.00 \times 10^{-4} \mathrm{M},[\mathrm{L}-\mathrm{Phenylalanine}]=5.00 \times 10^{-3} \mathrm{M},\left[\mathrm{KH}_{2} \mathrm{PO}_{4}\right]=4.80 \times 10^{-}$

${ }^{2}-0.144 \mathrm{M},\left[\mathrm{K}_{2} \mathrm{HPO}_{4}\right]=0.120-0.240 \mathrm{M}, \mathrm{pH}$ 6.66-7.47, 20.0-40.0 ${ }^{\circ} \mathrm{C} .{ }^{b}$ Activation parameters associated to the intercepts and slopes of the experimental rate constant versus $\left[\mathrm{H}^{+}\right]^{-1}$ plots. ${ }^{c}$ Errors associated to the activation parameters were calculated from the standard deviations for the intercept and slope of the Arrhenius and Eyring plots. 
Table 7. Thermodynamic and Kinetic Parameters Associated to Some Elementary Steps of the Non-Autocatalytic Reaction Pathway, ${ }^{a, b}$

\begin{tabular}{|c|c|c|c|}
\hline magnitude & value & unit & source \\
\hline$K_{\mathrm{I}}$ & $5.16 \times 10^{-10}$ & M & ref. (73) \\
\hline$k_{\mathrm{II}}$ & $(7 \pm 2) \times 10^{-3}$ & $M^{-1} s^{-1}$ & this work \\
\hline$k_{\mathrm{III}}$ & $1.8 \pm 0.2$ & $M^{-1} s^{-1}$ & this work \\
\hline$\Delta H_{\mathrm{I}}^{\mathrm{o}}$ & 44.6 & $\mathrm{~kJ} \mathrm{~mol}^{-1}$ & ref. (73) \\
\hline$E_{\mathrm{a}, \mathrm{II}}$ & $70 \pm 2$ & $\mathrm{~kJ} \mathrm{~mol}^{-1}$ & this work \\
\hline$E_{\mathrm{a}, \mathrm{IIII}}$ & $23 \pm 2$ & $\mathrm{~kJ} \mathrm{~mol}^{-1}$ & this work \\
\hline$\Delta H_{\neq, \mathrm{II}}^{\mathrm{o}}$ & $68 \pm 2$ & $\mathrm{~kJ} \mathrm{~mol}^{-1}$ & this work \\
\hline$\Delta H_{\neq, \mathrm{III}}^{\mathrm{o}}$ & $21 \pm 2$ & $\mathrm{~kJ} \mathrm{~mol}^{-1}$ & this work \\
\hline$\Delta S_{\mathrm{I}}^{\mathrm{o}}$ & -28.0 & $\mathrm{~J} \mathrm{~K}^{-1} \mathrm{~mol}^{-1}$ & ref. (73) \\
\hline$\Delta S_{\neq, \mathrm{II}}^{\mathrm{o}}$ & $-60 \pm 5$ & $\mathrm{~J} \mathrm{~K}^{-1} \mathrm{~mol}^{-1}$ & this work \\
\hline$\Delta S_{\neq, \mathrm{III}}^{\mathrm{o}}$ & $-171 \pm 6$ & $\mathrm{~J} \mathrm{~K}^{-1} \mathrm{~mol}^{-1}$ & this work \\
\hline
\end{tabular}

${ }^{a}$ The equilibrium and rate constants are given at $25.0^{\circ} \mathrm{C} .{ }^{b}$ The experimental errors associated to $E_{\mathrm{a}, \mathrm{III}}, \Delta H_{\neq, \mathrm{III}}^{\mathrm{o}}$ and $\Delta S_{\neq, \mathrm{III}}^{\mathrm{o}}$ are to be considered as lower limits. 

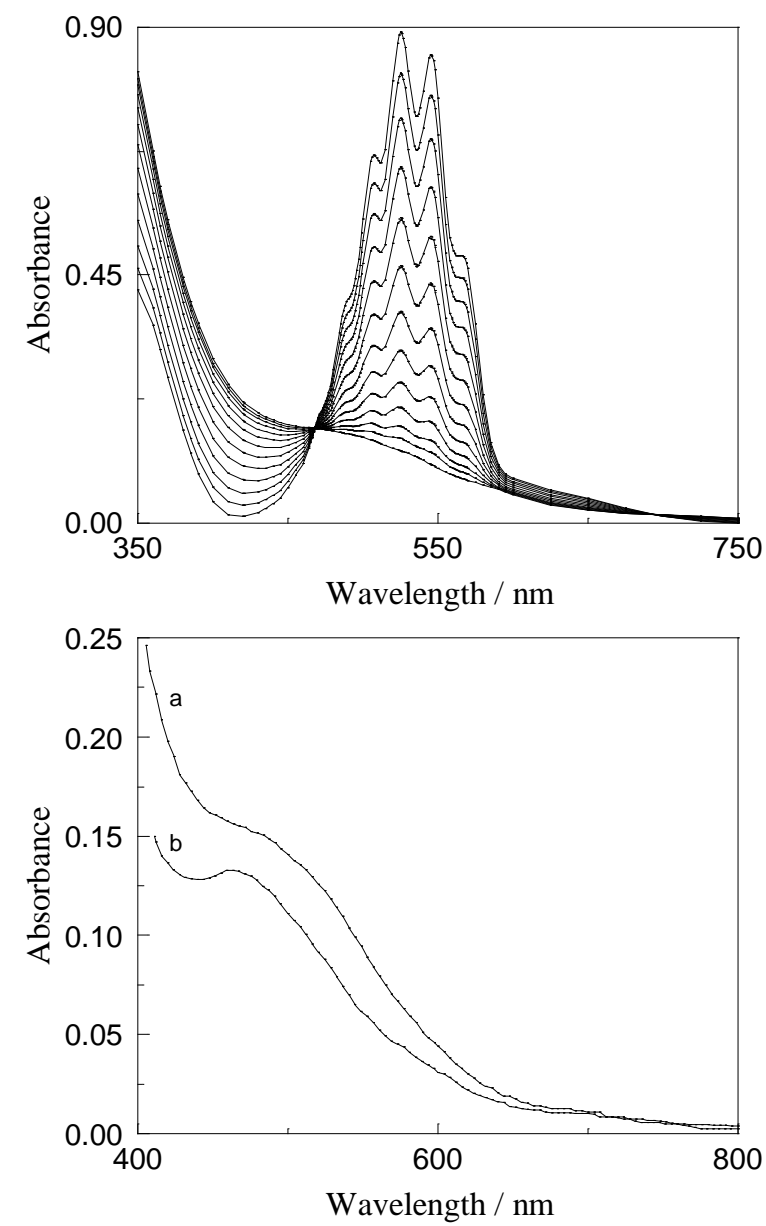

Figure 1. Visible spectra for the reduction of $\mathrm{KMnO}_{4}\left(4.00 \times 10^{-4} \mathrm{M}\right)$ at $\left[\mathrm{KH}_{2} \mathrm{PO}_{4}\right]=0.120$ $\mathrm{M},\left[\mathrm{K}_{2} \mathrm{HPO}_{4}\right]=0.150 \mathrm{M}, \mathrm{pH} 6.826 \pm 0.004$ and $25.0{ }^{\circ} \mathrm{C}$. Top: Periodical scanning at 50 -min intervals with [L-phenylalanine] $=5.00 \times 10^{-3} \mathrm{M}$. Bottom: Spectra recorded at times 62 (a) and 134 (b) min with [L-phenylalanine] $=5.00 \times 10^{-2} \mathrm{M}$. 

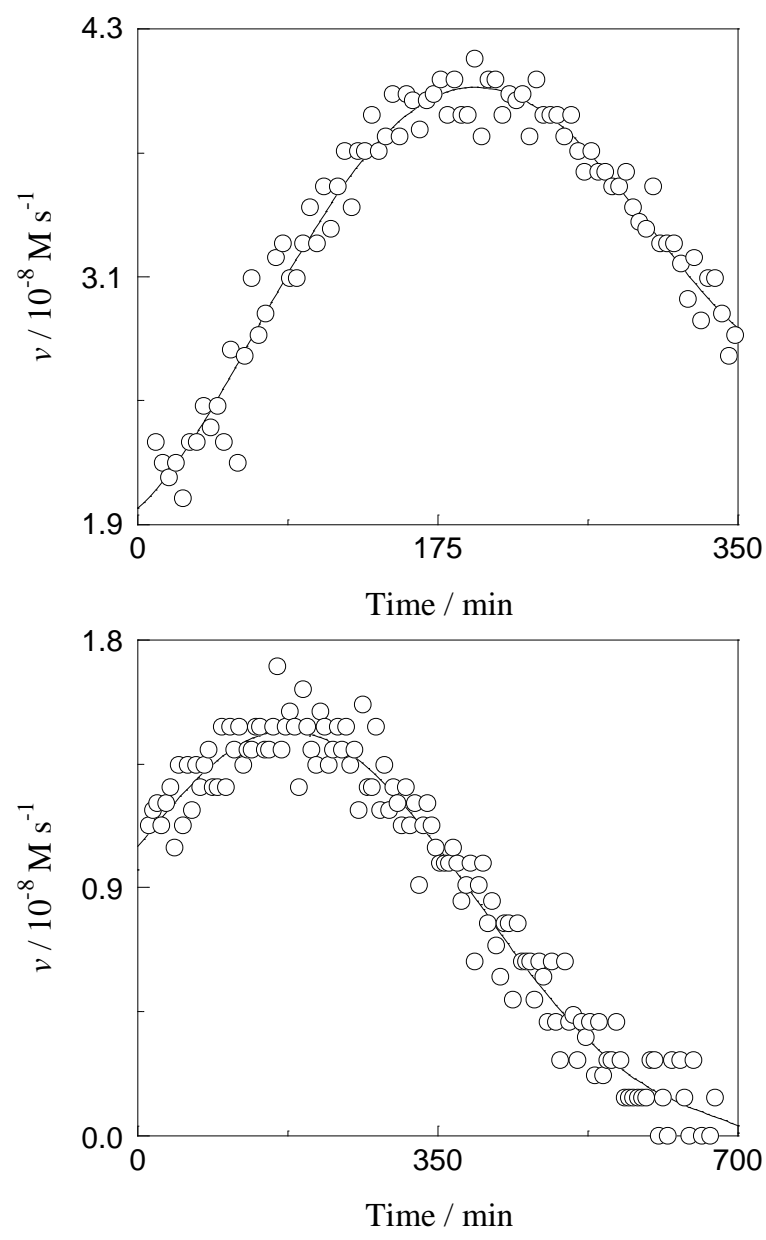

Figure 2. Reaction rate as a function of time at two different initial concentrations of $\mathrm{KMnO}_{4}: 4.00 \times 10^{-4}$ (bottom) and $1.00 \times 10^{-3}$ (top) $\mathrm{M}$. [L-phenylalanine] $=5.00 \times 10^{-3} \mathrm{M}$, $\left[\mathrm{KH}_{2} \mathrm{PO}_{4}\right]=0.120 \mathrm{M},\left[\mathrm{K}_{2} \mathrm{HPO}_{4}\right]=0.150 \mathrm{M}, \mathrm{pH} 6.826 \pm 0.004,25.0^{\circ} \mathrm{C}$. 


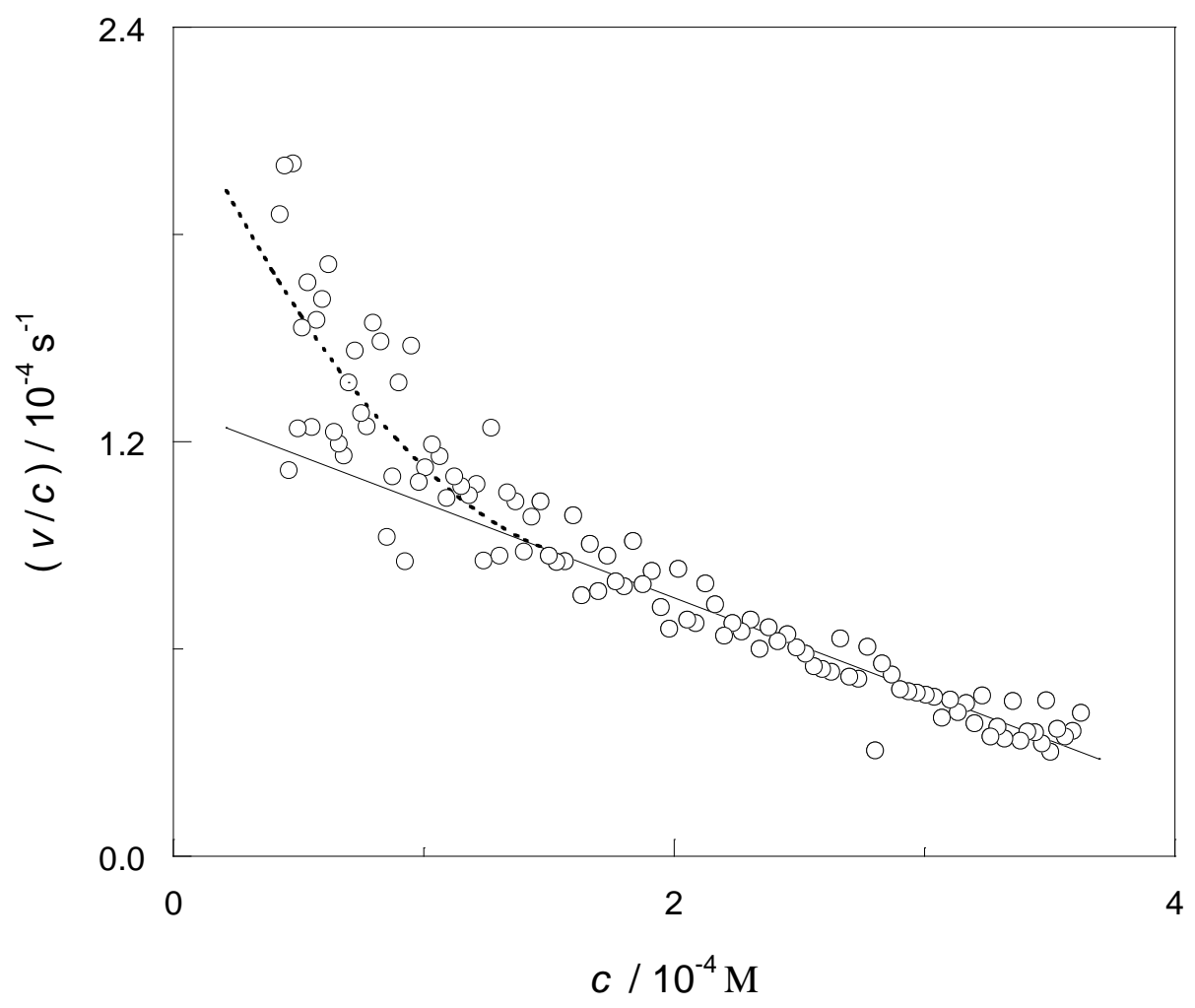

Figure 3. Reaction rate / permanganate concentration ratio as a function of the permanganate concentration calculated at 4-min intervals during the reduction of $\mathrm{KMnO}_{4}\left(4.00 \times 10^{-4} \mathrm{M}\right)$ by L-phenylalanine $\left(5.00 \times 10^{-3} \mathrm{M}\right)$ in the presence of $\mathrm{KH}_{2} \mathrm{PO}_{4}(0.120 \mathrm{M})-\mathrm{K}_{2} \mathrm{HPO}_{4}(0.150 \mathrm{M})$ buffer at $\mathrm{pH} 6.83$ and $25.0{ }^{\circ} \mathrm{C}$. The direction corresponding to the reaction progress is from right to left. 

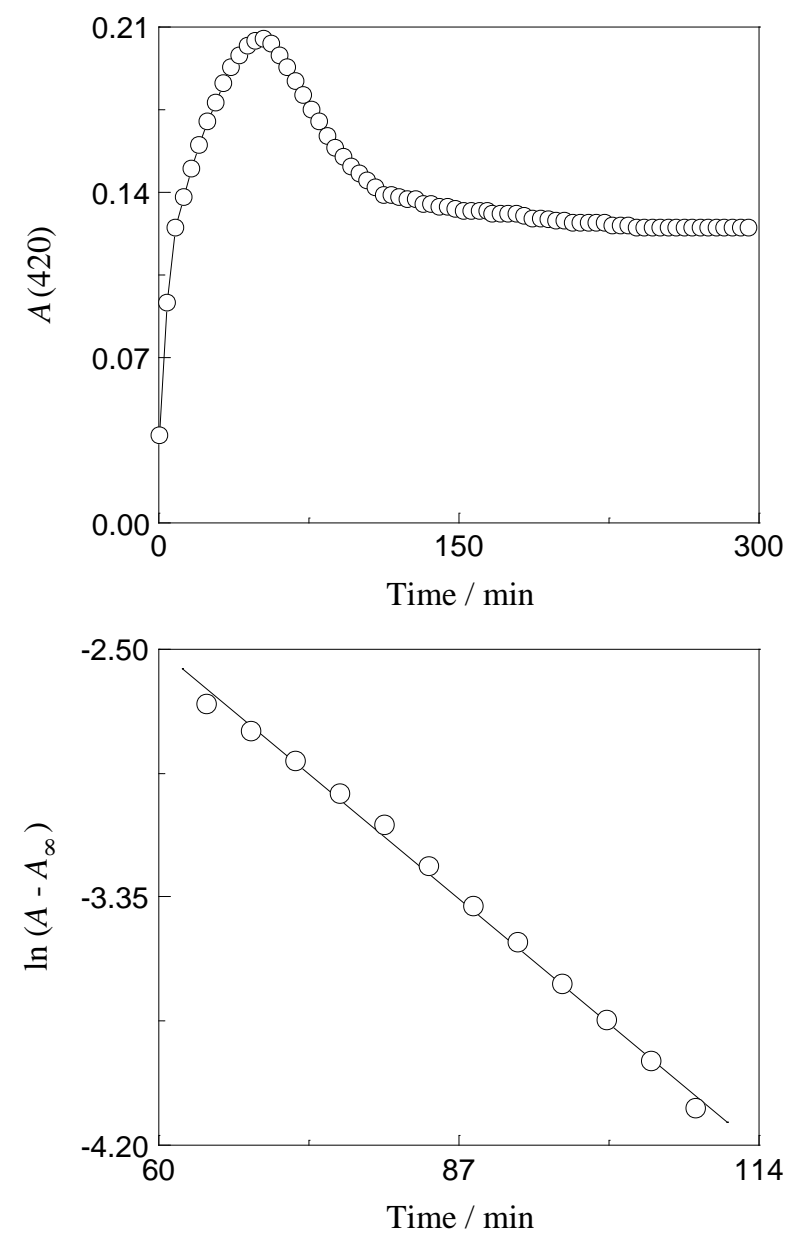

Figure 4. Reduction of $\mathrm{KMnO}_{4}\left(4.00 \times 10^{-4} \mathrm{M}\right)$ by L-phenylalanine $\left(5.00 \times 10^{-2} \mathrm{M}\right)$ in the presence of $\mathrm{KH}_{2} \mathrm{PO}_{4}(0.120 \mathrm{M})-\mathrm{K}_{2} \mathrm{HPO}_{4}(0.150 \mathrm{M})$ buffer at $\mathrm{pH} 6.83$ and $25.0{ }^{\circ} \mathrm{C}$. Top: Absorbance at $420 \mathrm{~nm}$ as a function of time. Bottom: Pseudo-first order plot for the reduction of $\mathrm{Mn}(\mathrm{IV})$ by the amino acid. 


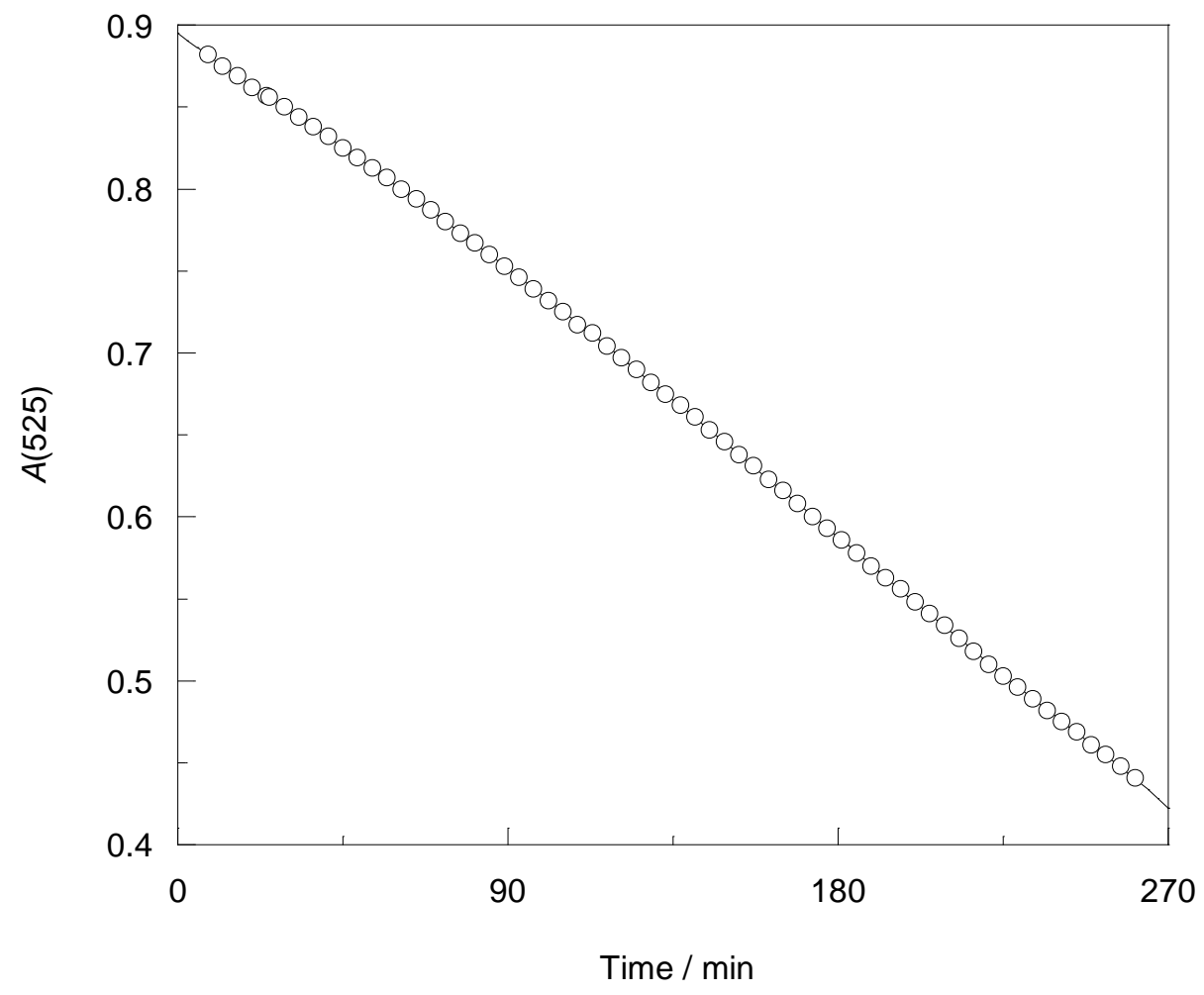

Figure 5. Absorbance at $525 \mathrm{~nm}$ as a function of time for the reduction of $\mathrm{KMnO}_{4}$ $\left(4.00 \times 10^{-4} \mathrm{M}\right)$ by L-phenylalanine $\left(5.00 \times 10^{-3} \mathrm{M}\right)$ in the presence of $\mathrm{KH}_{2} \mathrm{PO}_{4}(0.120$ $\mathrm{M})-\mathrm{K}_{2} \mathrm{HPO}_{4}(0.150 \mathrm{M})$ buffer at $\mathrm{pH} 6.83$ and $25.0{ }^{\circ} \mathrm{C}$. The circles correspond to the experimental absorbances and the continuous line to their simulated counterparts with $k_{1}=$ $3.36 \times 10^{-5} \mathrm{~s}^{-1}, k_{2}=3.49 \times 10^{-4} \mathrm{~s}^{-1}$ and $k_{3}=0.449 \mathrm{M}^{-1} \mathrm{~s}^{-1}$. 


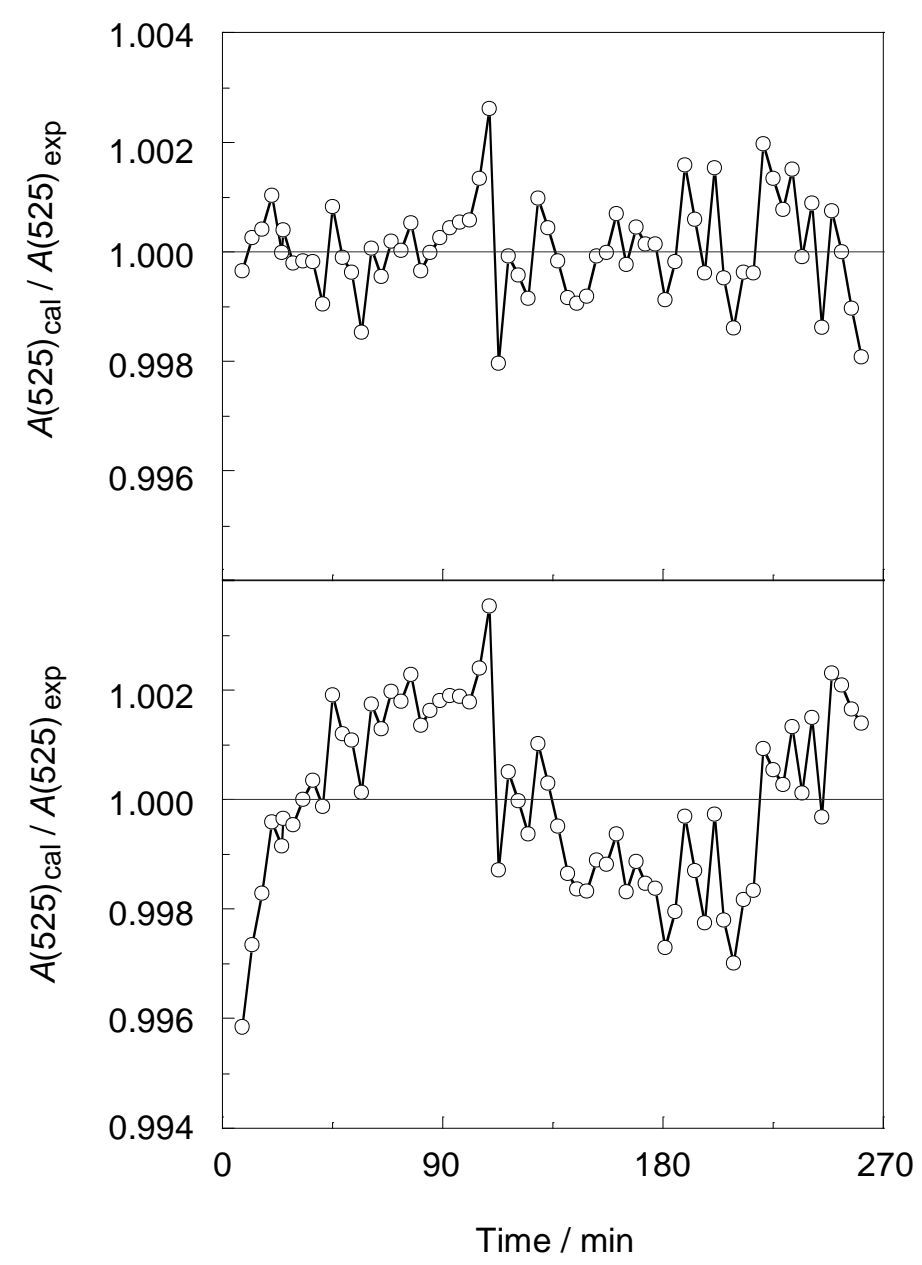

Figure 6. Ratio of the calculated and experimental absorbances at $525 \mathrm{~nm}$ as a function of time for the reduction of $\mathrm{KMnO}_{4}\left(4.00 \times 10^{-4} \mathrm{M}\right)$ by L-phenylalanine $\left(5.00 \times 10^{-3} \mathrm{M}\right)$ in the presence of $\mathrm{KH}_{2} \mathrm{PO}_{4}(0.120 \mathrm{M})-\mathrm{K}_{2} \mathrm{HPO}_{4}(0.150 \mathrm{M})$ buffer at $\mathrm{pH} 6.83$ and $25.0{ }^{\circ} \mathrm{C}$. Top: Three rate-constant mode (average error $E=4.19 \times 10^{-4}$ ). Bottom: Two rate-constant model (average error $E=9.14 \times 10^{-4}$ ). 


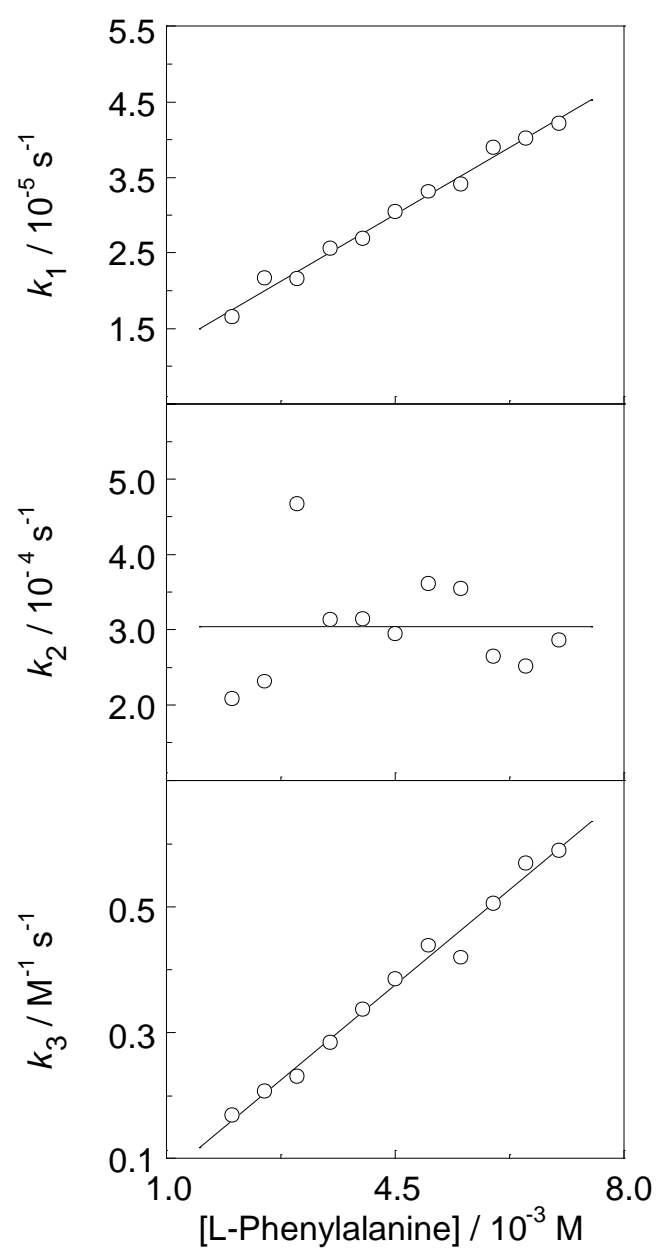

Figure 7. Experimental rate constants $k_{1}$ (top), $k_{2}$ (middle) and $k_{3}$ (bottom) as a function of the amino acid concentration for the reduction of $\mathrm{KMnO}_{4}\left(4.00 \times 10^{-4} \mathrm{M}\right)$ in the presence of $\mathrm{KH}_{2} \mathrm{PO}_{4}(0.120 \mathrm{M})-\mathrm{K}_{2} \mathrm{HPO}_{4}(0.150 \mathrm{M})$ buffer at $\mathrm{pH} \mathrm{pH} 6.826 \pm 0.004$ and $25.0{ }^{\circ} \mathrm{C}$. 


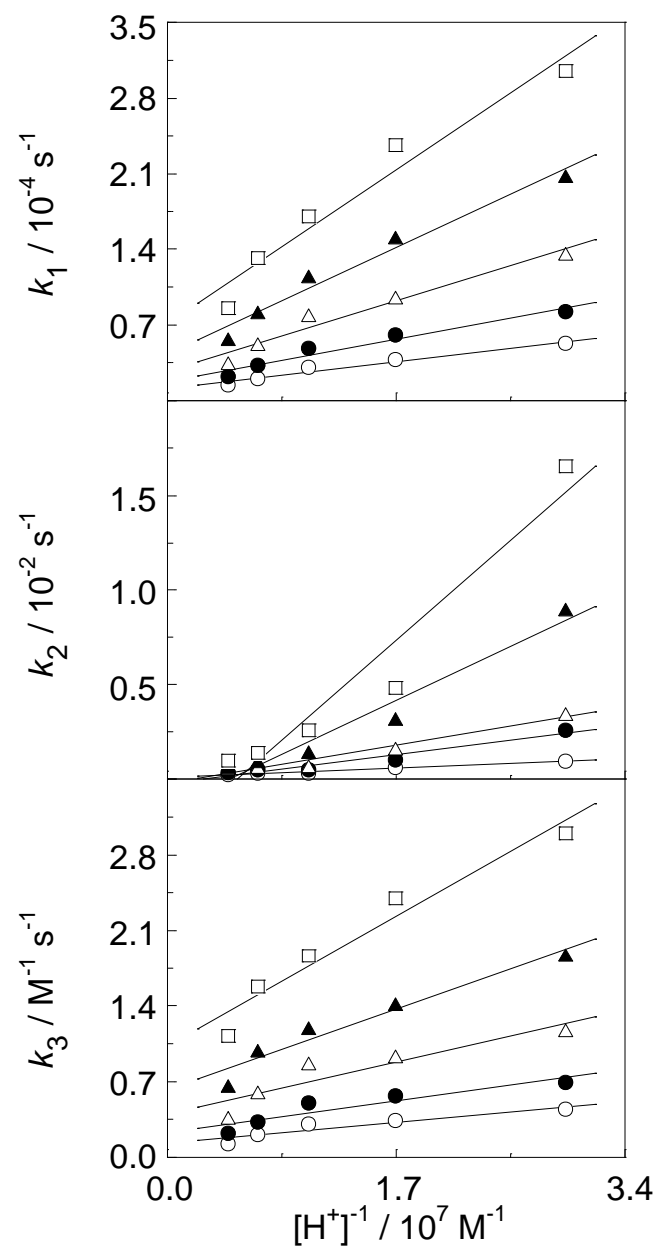

Figure 8. Experimental rate constants $k_{1}$ (top), $k_{2}$ (middle) and $k_{3}$ (bottom) as a function of the reciprocal of the hydrogen ion concentration for the reduction of $\mathrm{KMnO}_{4}\left(4.00 \times 10^{-4} \mathrm{M}\right)$ by L-phenylalanine $\left(5.00 \times 10^{-3} \mathrm{M}\right)$ in the presence of $\mathrm{KH}_{2} \mathrm{PO}_{4}\left(4.80 \times 10^{-2}-0.144 \mathrm{M}\right)-$ $\mathrm{K}_{2} \mathrm{HPO}_{4}(0.120-0.240 \mathrm{M})$ buffer at $\mathrm{pH} 6.66-7.47$ and temperatures of 20.0 (empty circles), 25.0 (filled circles), 30.0 (empty triangles), 35.0 (filled triangles) and 40.0 (squares) ${ }^{\circ} \mathrm{C}$. 

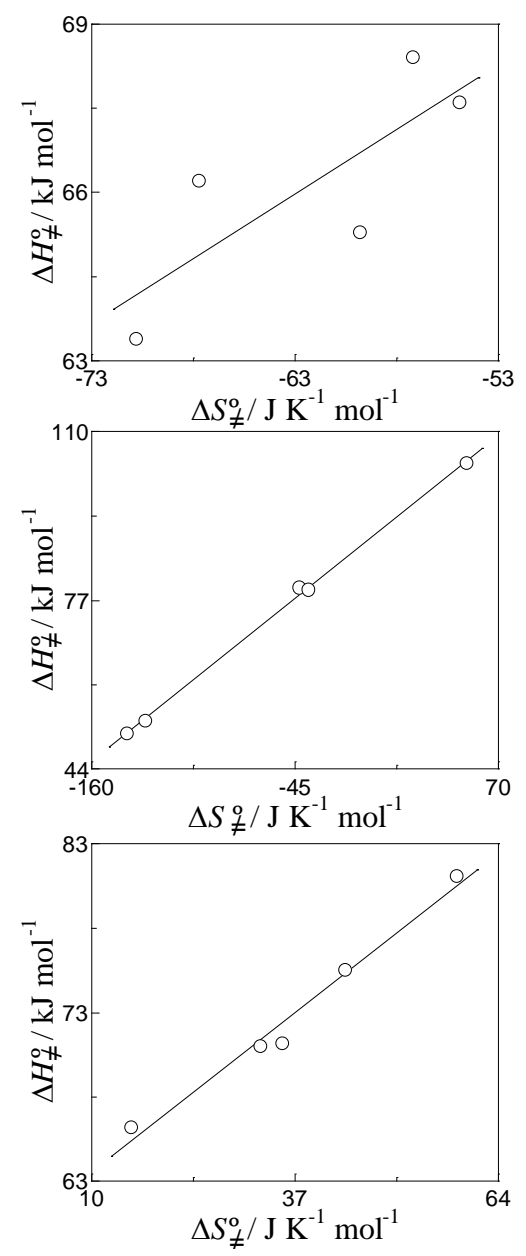

Figure 9. Attempted linear correlations between the apparent values of the activation parameters associated to the experimental rate constants $k_{1}$ (top, $T_{\mathrm{ik}}=229 \pm 99 \mathrm{~K}, r=0.8003$ ), $k_{2}\left(\right.$ middle, $\left.T_{\mathrm{ik}}=277 \pm 6 \mathrm{~K}, r=0.9994\right)$ and $k_{3}\left(\right.$ bottom, $\left.T_{\mathrm{ik}}=350 \pm 29 \mathrm{~K}, r=0.9896\right)$ for the reduction of $\mathrm{KMnO}_{4}\left(4.00 \times 10^{-4} \mathrm{M}\right)$ by L-phenylalanine $\left(5.00 \times 10^{-3} \mathrm{M}\right)$ in the presence of $\mathrm{KH}_{2} \mathrm{PO}_{4}\left(4.80 \times 10^{-2}-0.144 \mathrm{M}\right)-\mathrm{K}_{2} \mathrm{HPO}_{4}(0.120-0.240 \mathrm{M})$ buffer at 5 different $\mathrm{pH}$ values in the range $6.66-7.47$ and temperatures in the range $20.0-40.0^{\circ} \mathrm{C}$. 


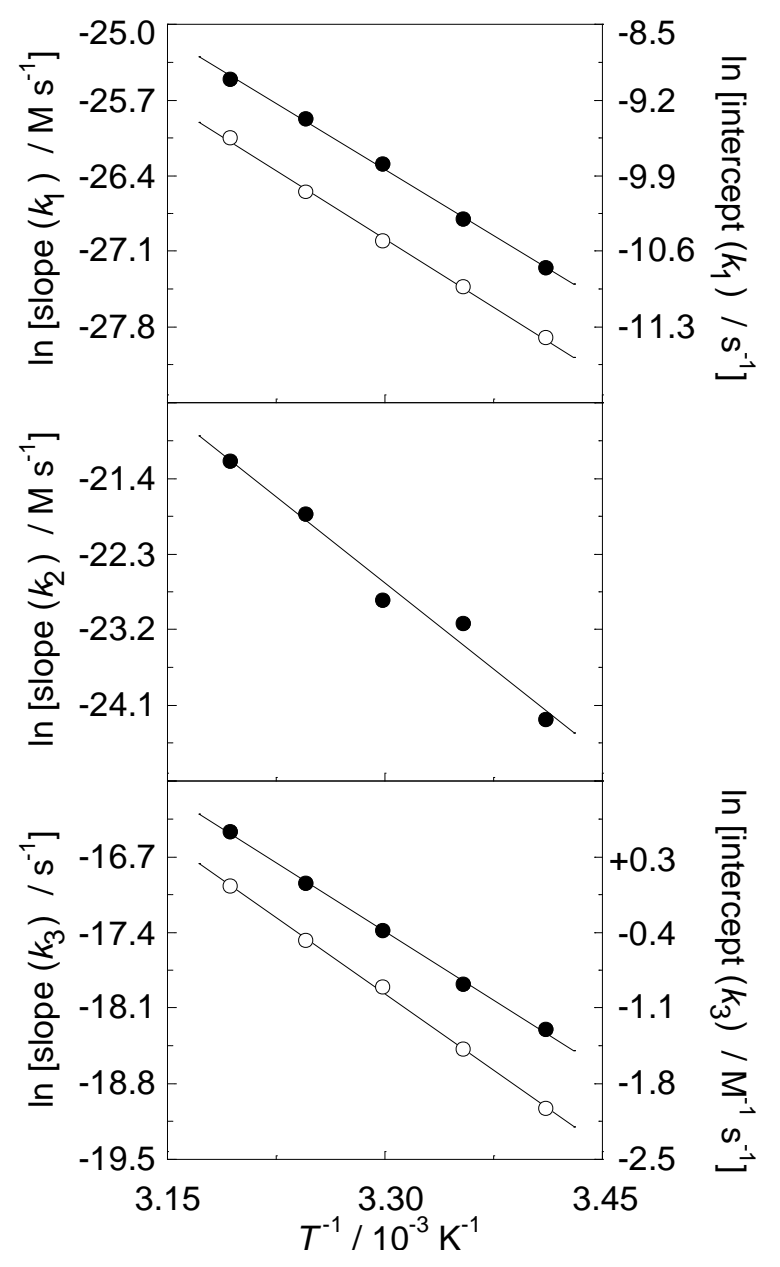

Figure 10. Arrhenius plots for the intercepts (empty circles) and slopes (filled circles) of the rate constant versus $\left[\mathrm{H}^{+}\right]^{-1}$ linear correlations associated to the experimental rate constants $k_{1}$ (top), $k_{2}$ (middle) and $k_{3}$ (bottom) for the reduction of $\mathrm{KMnO}_{4}\left(4.00 \times 10^{-4} \mathrm{M}\right)$ by Lphenylalanine $\left(5.00 \times 10^{-3} \mathrm{M}\right)$ in the presence of $\mathrm{KH}_{2} \mathrm{PO}_{4}\left(4.80 \times 10^{-2}-0.144 \mathrm{M}\right)-\mathrm{K}_{2} \mathrm{HPO}_{4}$ $(0.120-0.240 \mathrm{M})$ buffer at $\mathrm{pH} 6.66-7.47$ and $20.0-40.0^{\circ} \mathrm{C}$. 
"Table of Contents" Graphic

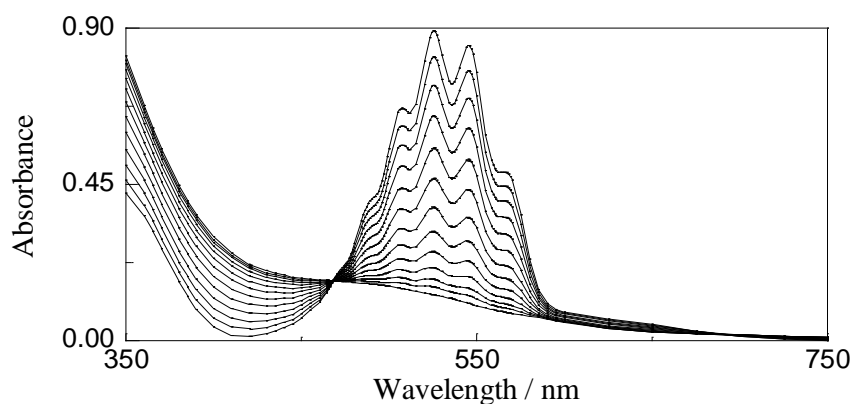

